Article

\title{
Effect of Drying Methods on Lutein Content and Recovery by Supercritical Extraction from the Microalga Muriellopsis sp. (MCH35) Cultivated in the Arid North of Chile
}

\author{
Mari Carmen Ruiz-Domínguez ${ }^{1, *(1)}$, Paola Marticorena ${ }^{2}$, Claudia Sepúlveda ${ }^{2}$, \\ Francisca Salinas ${ }^{1}$ (D), Pedro Cerezal ${ }^{1}$ and Carlos Riquelme ${ }^{2}$ \\ 1 Laboratorio de Microencapsulación de Compuestos Bioactivos (LAMICBA), Departamento de Ciencias de \\ los Alimentos y Nutrición, Facultad de Ciencias de la Salud, Universidad de Antofagasta, \\ Antofagasta 1240000, Chile; francisca.salinas@uantof.cl (F.S.); pedro.cerezal@uantof.cl (P.C.) \\ 2 Centro de Bioinnovación, Facultad de Ciencias del Mar y Recursos Biológicos, Universidad de Antofagasta, \\ Antofagasta 1240000, Chile; marticorena.paola@gmail.com (P.M.); claudia.sepulveda@uantof.cl (C.S.); \\ carlos.riquelme@uantof.cl (C.R.) \\ * Correspondence: maria.ruiz@uantof.cl; Tel.: +56-552-633-660
}

Received: 30 September 2020; Accepted: 14 October 2020; Published: 26 October 2020

check for updates

\begin{abstract}
In this study, we determined the effect of drying on extraction kinetics, yield, and lutein content and recovery of the microalga Muriellopsis sp. (MCH35) using the supercritical fluid extraction (SFE) process. The strain was cultivated in an open-raceways reactor in the presence of seawater culture media and arid outdoor conditions in the north of Chile. Spray-drying (SD) and freeze-drying (FD) techniques were used for dehydrating the microalgal biomass. Extraction experiments were performed by using Box-Behnken designs, and the parameters were studied: pressure (30-50 MPa), temperature $\left(40-70{ }^{\circ} \mathrm{C}\right)$, and co-solvent $\left(0-30 \%\right.$ ethanol), with a $\mathrm{CO}_{2}$ flow rate of $3.62 \mathrm{~g} / \mathrm{min}$ for $60 \mathrm{~min}$. Spline linear model was applied in the central point of the experimental design to obtain an overall extraction curve and to reveal extraction kinetics involved in the SFE process. A significant increase in all variables was observed when the level of ethanol $(15-30 \% v / v)$ was increased. However, temperature and pressure were non-significant parameters in the SFE process. The FD method showed an increase in lutein content and recovery by $0.3-2.5$-fold more than the SD method. Overall, Muriellopsis sp. (MCH35) is a potential candidate for cost-effective lutein production, especially in desert areas and for different biotechnological applications.
\end{abstract}

Keywords: microalgae; Muriellopsis; spray drying; freeze-drying; lutein; supercritical fluid extraction

\section{Introduction}

In the past few decades, demand for bioprospection of microorganisms isolated from harsh environmental conditions has been increased because of their diverse biotechnological applications. Among microorganisms, microalgae are the most diversified photosynthetic organisms with high adaptability to different environmental conditions [1]. They are mainly classified as Cyanophyta (cyanobacteria), Rhodophyta (red algae), Chlorophyta (green algae), and Chromophyta (brown algae) $[2,3]$.

Microalgae are characterized as natural sources of bioactive molecules such as phycobiliproteins, polysaccharides, carotenoids, lipids, fatty acids, polyphenols, and vitamins [4,5]. These compounds exhibit health benefits such as antibacterial, antifungal, antioxidant, and anticancer activities that are essential in pharmacological, nutraceutical, food, and biotechnological development [5-7]. 
Carotenoids belong to the class of terpenoids and are derived from the 40-carbon polyene chain and xanthophylls as their oxygenated derivatives in the presence of -OH groups (e.g., lutein), oxi-groups (e.g., canthaxanthin), or both (e.g., astaxanthin) [8-10]. Pure lutein is an orange-yellow, crystalline, and lipophilic solid whose chemical name is $\beta, \varepsilon$-carotene-3,3'-diol $\left(\mathrm{C}_{40} \mathrm{H}_{56} \mathrm{O}_{2}\right)$. It is beneficial to human health due to its potential to ameliorate cardiovascular diseases [11], various types of cancer [12], and age-related macular degeneration [13] because of its antioxidant potential. The species known to accumulate carotenoids efficiently are Chlorella sp., Chlamydomonas sp., Dunaliella sp., Muriellopsis sp., and Haematococcus sp.

In this study, we used Muriellopsis sp. (MCH35), having the potential of producing carotenoids, especially lutein, as the main oxygenated carotenoid. This strain was isolated from an arid region of the north of Chile, as described previously by Marticorena et al. [14]. This area is located in Antofagasta, a well-known region for its high solar radiation, an environmental factor that favors microalgal growth [15]. Several studies have reported strategies to enhance microalgal carotenoid production using unfavorable environmental conditions such as nutrient deficiency, intense irradiation, and salinity to photo-bioreactors design [16-18]. These factors affect not only photosynthesis and productivity of cell biomass, but also pathways and cellular metabolism, and thus alter the cell composition [16]. The isolation and selection of microalgae is a prerequisite for the successful industrial production of biomass and beneficial compounds. Two factors are important in their successful industrial production: lutein content and biomass productivity. Other factors, such as the presence of cell wall or content of other carotenoids, can also be considered. A high lutein content in microalgae is necessary to achieve cost-effective and adequate amounts of extraction [19].

After the harvesting process, microalgal biomass pretreatment and extraction of bioactive compounds are most important because of their effect on bioactive molecule recovery. A drying process is the most common pretreatment method that increases the shelf life of naturally occurring bioactive biomass $[20,21]$. A dehydration process represents an essential step for reducing microbial growth, avoiding oxidative reactions, and improving bioactive compound extraction, although they are expensive [22-24]. However, these methods can alter the stability of labile bioactive compounds because of thermal breakdown [25]. Therefore, techniques such as spray-drying (SD) or freeze-drying (FD) that can adjust drying temperature have been recommended by researchers [23]. For the extractions of bioactive compounds, such as carotenoid from microalgae, many conventional methods, including maceration or soxhlet extraction, are used [19]. However, these methods are extensive and require a relatively huge amount of solvents, and thus are expensive and less eco-friendly [26]. Therefore, the use of green extraction technologies is increasing for the extraction of bioactive compounds. Green extraction technologies enhance extraction time, recovery, selectivity, and mass transfer with decreasing consumption of solvents. Supercritical fluid extraction (SFE), pressurized liquid extraction, microwave-assisted extraction, ultrasound-assisted extraction, and high-pressure homogenization are some examples of green extraction technologies [26].

The aim of this work is to study the effect of two different methods of biomass drying on lutein content and recovery, extraction kinetics, and yield of Muriellopsis sp. extracted by using the SFE process. The microalga was cultured in an open-raceways reactor under adapted outdoor conditions in the arid north of Chile. After harvesting of cells, SD and FD methods were employed for removing water content from the microalgal biomass and for knowing an individual carotenoid benchmark profile by using conventional methods. In the case of SFE, the parameters such as temperature $\left(40-70{ }^{\circ} \mathrm{C}\right)$, pressure (30-50 MPa), and percentage of co-solvent (0-30\% ethanol) were studied on the basis of Box-Behnken designs. In a similar way, the Spline linear model was used to control parameters for optimal lutein recovery from Muriellopsis sp. (MCH35). Drying pretreatment and optimal lutein extraction parameters for the microalgal biomass were studied with a focus on using the strain for future biotechnological applications and minimizing production cost when grown on a pilot-scale in a harsh environment. 


\section{Results and Discussion}

\subsection{Growth Parameters and Carotenoid Profile of Muriellopsis sp. (MCH35)}

Photoautotrophic cultivation is a growing condition wherein light is an energy source, and carbon dioxide is an inorganic carbon source used to form chemical energy by using photosynthesis [27]. To evaluate the growth performance and parameters of Muriellopsis sp. (MCH35), batch tests were performed by using UMA5 culture medium [28]. The specific growth rate $(\mu)$ was found to be $0.085 \mathrm{~d}^{-1}$, as calculated by using Equation (1),

$$
\mu=\operatorname{Ln}(C)(C i) / t
$$

and is in accordance with previously reported data on the green microalga Nannochloropsis gaditana with similar environmental conditions, such as sufficient light and nutrient availability [29]. Therefore, the UMA5 culture medium is suitable for the cultivation of Muriellopsis sp. (MCH35) as it contains an adequate amount of nutrients required for the microalga. Nitrogen concentration and nitrogen:phosphorus ratio are widely recognized as determining factors for the growth and composition of microalgae [30,31]. An exponential increase was observed from day 0 to day 12 in biomass concentration starting with $0.44 \mathrm{~g} / \mathrm{L}$ and reaching to the final concentration of $1.34 \mathrm{~g} / \mathrm{L}$ (Figure 1A).

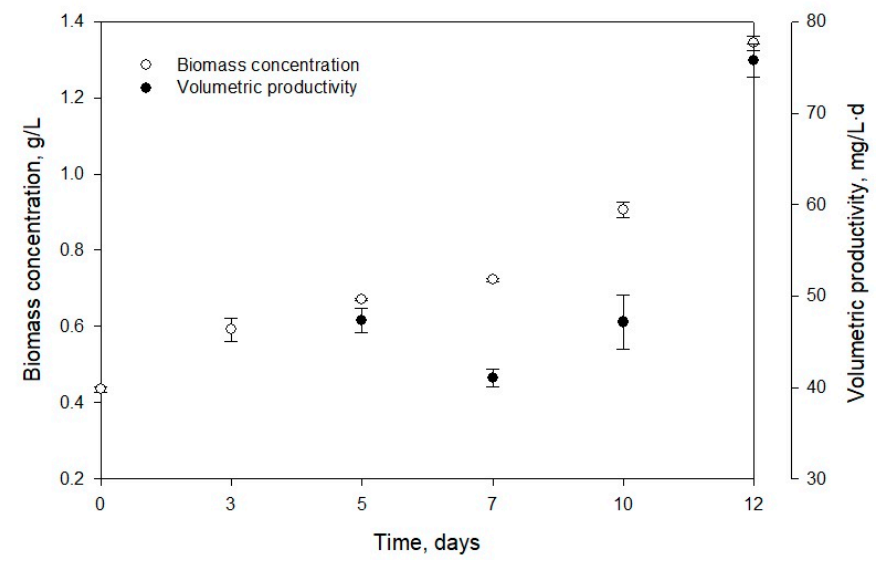

(A)

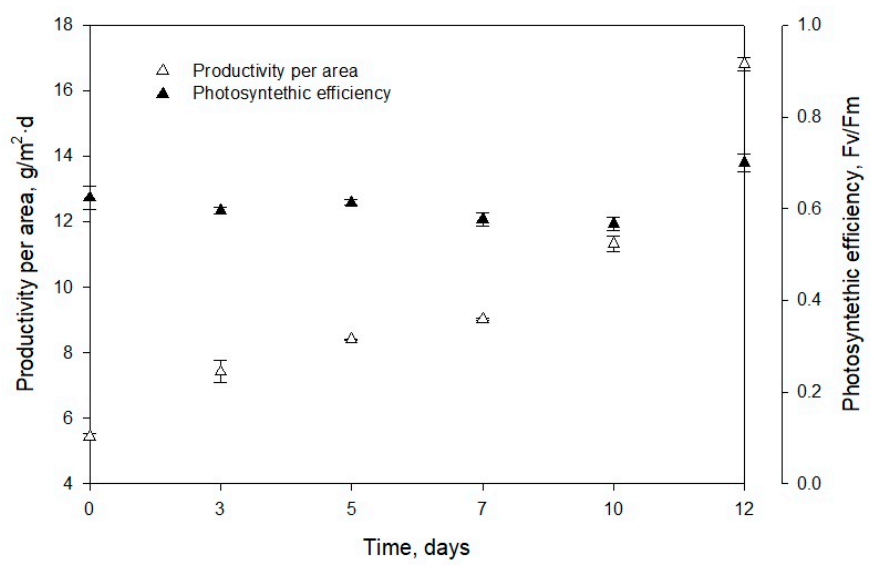

(B)

Figure 1. Evolution of (A) biomass concentration and volumetric productivity, and (B) productivity per area and photosynthetic efficiency of the strain Muriellopsis sp. (MCH35) in batch mode culture adapted under outdoor conditions in the arid north of Chile. 
Chew et al. [32] reported the Dunaliella sp. biomass concentration of $1.5 \mathrm{~g} / \mathrm{L}$ (in a volume of $3.4 \mathrm{~L}$ ) at the laboratory scale. For Phaeodactylum sp., the biomass concentration of $1.38 \mathrm{~g} / \mathrm{L}$ in $5 \mathrm{~L}$ medium was observed, while for Chlorella vulgaris, it was in the range of 0.6 to $1.08 \mathrm{~g} / \mathrm{L} \cdot \mathrm{d}$ (in a volume of $1.5 \mathrm{~L}$ ). Similar values were obtained for the first two strains, and the difference in biomass productivity of Muriellopsis sp. and Chlorella vulgaris can be due to the optimized laboratory conditions and differences in sizes of the two strains. The volumetric productivity of Muriellopsis sp. culture reached $75.73 \mathrm{mg} / \mathrm{L} \cdot \mathrm{d}$ on day 12 , and the productivity per area was $16.81 \mathrm{~g} / \mathrm{m}^{2} \cdot \mathrm{d}$ (Figure 1A,B). High productivity was reported in the Nannochloropis gaditana cultures with $400 \mathrm{mg} / \mathrm{L} \cdot \mathrm{d}$ and incident irradiance of $1.100 \mu \mathrm{E} / \mathrm{m}^{2} \cdot \mathrm{s}[33]$. Our experiments on Muriellopsis sp. were carried out with an incident irradiance of $1.400 \mu \mathrm{E} / \mathrm{m}^{2} \cdot \mathrm{s}$, under outdoor conditions. The difference in productivities can be due to the different cultivation modes used, as a batch mode can affect productivity compared with semi-continuous mode. During the cultivation, it is essential to determine the variation in chlorophyll fluorescence (Fv/Fm) by focusing on the suitability of culture conditions. This parameter represents a measure of the quantum yield of PSII (photosystem II) and identifies any damage to the protein complex caused by photo-inhibition [34]. Figure 1B shows the values of photosynthetic efficiency ranging from 0.58 to 0.7 during the cultivation. An acceptable level of physiological acclimatization exhibited by Muriellopsis sp. was confirmed in our study (Figures 1B and 2). In optimal cultivation conditions, the productivity of Muriellopsis sp. was $\sim 0.60$ at a $\mathrm{pH}$ of $7.9-8.2$ and temperature of $16.3-19.6{ }^{\circ} \mathrm{C}$, when cultivated in a semi-continuous mode by using Arnon culture medium [35]. Del Campo et al. [36] determined the limiting growth conditions such as $\mathrm{pH}$ of $6-9$ and the temperature of $33^{\circ} \mathrm{C}$ that stimulated carotenogenesis in Muriellopsis sp.

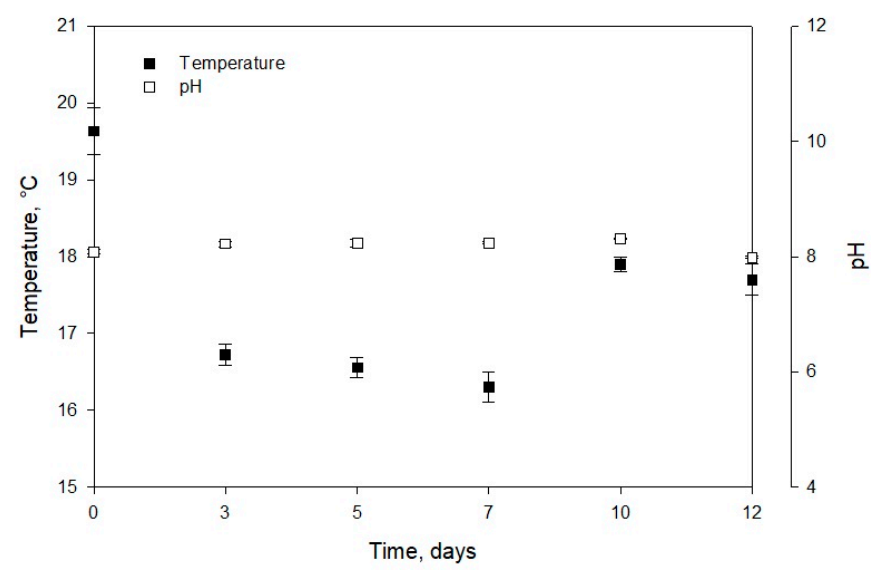

Figure 2. Temperature and $\mathrm{pH}$ and evolution of Muriellopsis sp. (MCH35) in a batch mode culture adapted under outdoor conditions in the arid north of Chile.

The main carotenoids present in the SD and FD biomass are shown in Table 1. These data are supported by Figure 3, showing an HPLC chromatogram with a diode array detector from the FD microalga.

Table 1. Individual carotenoid profiles present in Muriellopsis sp. (MCH35) from two modes of dry biomass by the conventional method of extraction.

\begin{tabular}{cccccc}
\hline \multirow{2}{*}{ Biomass } & \multicolumn{5}{c}{ Carotenoids Content (mg/g Biomass) ${ }^{*}$} \\
\cline { 2 - 5 } & Lutein & Zeaxanthin & Violaxanthin & Astaxanthin & $\beta$-carotene \\
\hline Spray-dried (SD) & $3.45 \pm 0.20^{\mathrm{b}}$ & $0.60 \pm 0.04^{\mathrm{b}}$ & $0.15 \pm 0.10^{\mathrm{a}}$ & $0.45 \pm 0.15^{\mathrm{a}}$ & $0.45 \pm 0.04^{\mathrm{b}}$ \\
Freeze-dried (FD) & $4.20 \pm 0.30^{\mathrm{a}}$ & $0.75 \pm 0.06^{\mathrm{a}}$ & $0.30 \pm 0.20^{\mathrm{a}}$ & $0.30 \pm 0.02^{\mathrm{b}}$ & $0.60 \pm 0.05^{\mathrm{a}}$ \\
\hline
\end{tabular}

* Benchmark extraction. Mean values in the same column followed by different letters (a-b) are significantly different $(p<0.05)$. 


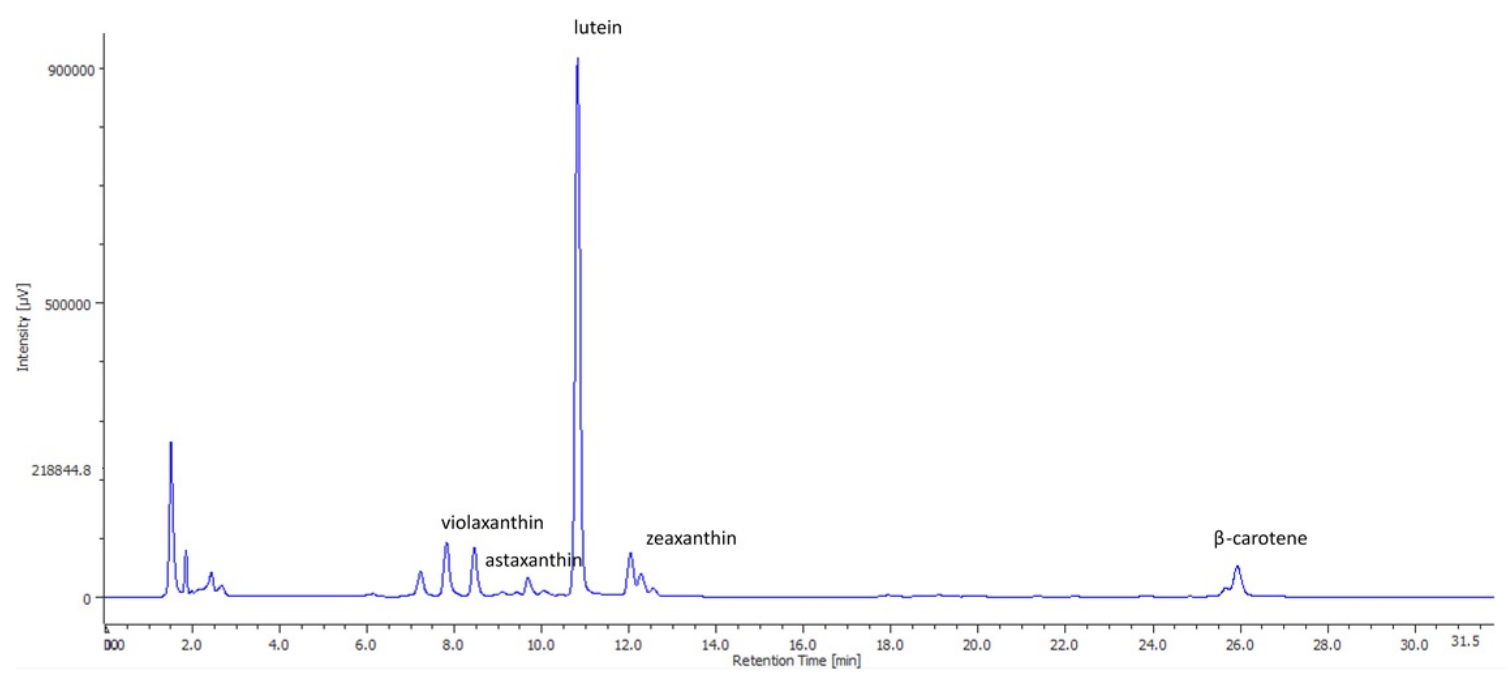

Figure 3. HPLC (High Performance Liquid Chromatography) chromatogram of individual carotenoids present in Muriellopsis sp. (MCH35), extracted under conventional extraction (freeze-dried (FD) biomass) and measured at $450 \mathrm{~nm}$ by a diode array detector.

The high individual carotenoid content was observed in FD biomass, except for astaxanthin that was 1.5 times higher for the SD method than the FD method. A similar drying effect was reported by Ryckebosch et al. [37] in which they evaluated the effect of the SD and FD methods on fresh biomass and the storage stability of lipids and carotenoids in the diatom Phaeodactylum tricornutum. Their study showed better results on carotenoid contents in the fresh and FD biomass of algae than that in SD biomass at $48 \mathrm{~h}$ (denominated as short-term storage). Lutein is the main carotenoid profile that Muriellopsis sp. shows [19,36,38]. Our results on lutein content (particularly lyophilized cells) were in a similar range with that reported previously (in range of 4.0 to $6.0 \mathrm{mg} / \mathrm{g}$ dry weight) $[39,40]$. Better lutein content was obtained by using both the drying methods than that reported by Molino et al. [41], who studied lutein production in different microalgae in a comparative manner. Our results were in a similar range as that reported by Del Campo et al. [8] and had an advantage that our cultures were produced at a large scale using seawater. This is relevant when developing massive cultures in areas with scarce water resources, such as desert areas (Antofagasta Region).

We found other carotenoids such as zeaxanthin, violaxanthin, astaxanthin, and $\beta$-carotene (can be seen in Figure 3) in low levels in Muriellopsis sp., similar to those reported by Del Campo et al. [36], with a total concentration of $5.10 \pm 0.53$ and $6.15 \pm 0.63 \mathrm{mg} / \mathrm{g}$ for the SD and FD processes, respectively. Despite their low levels in Muriellopsis sp., their presence can contribute to pharmacological, nutraceutical, food, and biotechnological applications [7,42]. Lutein and zeaxanthin reduce age-related macular degeneration [43], while $\beta$-carotene prevents cataracts, skin diseases, and other illnesses like cancer [42,44]. Moreover, violaxanthin is a potential anti-photoaging agent acting against ultraviolet-B radiation (UV-B; $\lambda 280-315 \mathrm{~nm}$ ) [45], and astaxanthin is considered super vitamin E [46] for its stronger antioxidant activity (500 times more effective than $\alpha$-tocopherol), preventing arteriosclerosis, coronary heart disease, and ischemic brain development $[42,46]$. Therefore, although it would be beneficial to optimize the extraction technology of lutein as suggested by Di Caprio et al. [47], our results provide preliminary information on the carotenoid profile of Muriellopsis sp. (MCH35).

\subsection{Effects of Drying Processes on the Extraction Yield of Muriellopsis sp. (MCH35) by SFE}

The experimental extraction conditions and results of the Box-Behnken designs from two-mode dry biomass by the SFE process are given in Table 2. The range of extraction yield $(\mathrm{Y})$ was $0.11-7.84 \%(w / w)$ for the SD biomass and $0.76-6.05 \%(w / w)$ for the FD biomass. Table 2 shows the effect of co-solvent on extraction yield at all the conditions. The low levels of extracts were obtained without the addition of the modifier, such as $0.11-0.44 \%$ for the SD and $0.76-2.07 \%$ for the FD biomass. 
Table 2. Extraction yields (Y) and lutein content and recovery by SFE from spray- and freeze-dried Muriellopsis sp. (MCH35) using Box-Behnken experimental design. The general parameters were biomass loading $=2.0 \mathrm{~g}, \mathrm{CO}_{2}$ flow rate $=3.62 \mathrm{~g} / \mathrm{min}$, and extraction time $=60 \mathrm{~min}$.

\begin{tabular}{|c|c|c|c|c|c|c|c|}
\hline Biomass & Run & $\begin{array}{c}\mathrm{T} \\
\left({ }^{\circ} \mathrm{C}\right)\end{array}$ & $\begin{array}{c}\mathrm{P} \\
(\mathrm{MPa})\end{array}$ & $\begin{array}{l}\text { Ethanol } \\
(\%, v / v)\end{array}$ & $\begin{array}{l}\text { Yield } \\
(\%, w / w)\end{array}$ & $\begin{array}{l}\text { Lutein Content } \\
\text { (mg/g Extract) }\end{array}$ & $\begin{array}{c}\text { Lutein Recovery } \\
(\%, w / w)\end{array}$ \\
\hline \multirow{15}{*}{ Spray-dried } & 1 & 40 & 30 & 15 & $1.52 \pm 0.08$ & $45.47 \pm 1.45$ & $20.05 \pm 0.48$ \\
\hline & 2 & 70 & 30 & 15 & $1.84 \pm 0.09$ & $43.95 \pm 0.10$ & $23.38 \pm 0.13$ \\
\hline & 3 & 40 & 50 & 15 & $1.63 \pm 0.08$ & $34.27 \pm 0.36$ & $16.23 \pm 0.04$ \\
\hline & 4 & 70 & 50 & 15 & $2.17 \pm 0.02$ & $34.70 \pm 0.21$ & $21.79 \pm 0.92$ \\
\hline & 5 & 40 & 40 & 0 & $0.11 \pm 0.01$ & $2.60 \pm 0.03$ & $0.09 \pm 0.3 \times 10^{-3}$ \\
\hline & 6 & 70 & 40 & 0 & $0.42 \pm 0.02$ & $6.28 \pm 0.06$ & $0.76 \pm 1.2 \times 10^{-3}$ \\
\hline & 7 & 40 & 40 & 30 & $1.87 \pm 0.09$ & $27.69 \pm 0.31$ & $15.04 \pm 0.05$ \\
\hline & 8 & 70 & 40 & 30 & $2.31 \pm 0.08$ & $23.69 \pm 0.34$ & $15.86 \pm 0.14$ \\
\hline & 9 & 55 & 30 & 0 & $0.32 \pm 0.10$ & $1.27 \pm 0.02$ & $0.12 \pm 0.03$ \\
\hline & 10 & 55 & 50 & 0 & $0.44 \pm 0.02$ & $7.80 \pm 10^{-3}$ & $0.99 \pm 0.01$ \\
\hline & 11 & 55 & 30 & 30 & $7.84 \pm 0.27$ & $13.30 \pm 0.11$ & $30.23 \pm 0.45$ \\
\hline & 12 & 55 & 50 & 30 & $1.72 \pm 0.06$ & $43.76 \pm 0.41$ & $21.76 \pm 0.30$ \\
\hline & 13 & 55 & 40 & 15 & $1.67 \pm 0.03$ & $31.21 \pm 0.12$ & $15.12 \pm 0.52$ \\
\hline & 14 & 55 & 40 & 15 & $1.70 \pm 0.09$ & $47.14 \pm 0.75$ & $23.25 \pm 0.18$ \\
\hline & 15 & 55 & 40 & 15 & $1.57 \pm 0.03$ & $38.68 \pm 0.10$ & $17.65 \pm 0.63$ \\
\hline Biomass & Run & $\begin{array}{c}\mathrm{T} \\
\left({ }^{\circ} \mathrm{C}\right)\end{array}$ & $\begin{array}{c}\mathrm{P} \\
(\mathrm{MPa})\end{array}$ & $\begin{array}{l}\text { Ethanol } \\
(\%, v / v)\end{array}$ & $\begin{array}{c}\text { Yield } \\
(\%, w / w)\end{array}$ & $\begin{array}{l}\text { Lutein Content } \\
\text { (mg/g Extract) }\end{array}$ & $\begin{array}{c}\text { Lutein Recovery } \\
(\%, w / w)\end{array}$ \\
\hline \multirow{15}{*}{ Freeze-dried } & 16 & 40 & 30 & 15 & $4.79 \pm 0.24$ & $25.96 \pm 1.18$ & $29.62 \pm 0.71$ \\
\hline & 17 & 70 & 30 & 15 & $4.55 \pm 0.16$ & $46.00 \pm 0.26$ & $49.84 \pm 1.54$ \\
\hline & 18 & 40 & 50 & 15 & $1.62 \pm 0.08$ & $60.69 \pm 2.06$ & $23.39 \pm 0.29$ \\
\hline & 19 & 70 & 50 & 15 & $2.32 \pm 0.05$ & $53.69 \pm 2.41$ & $29.64 \pm 0.20$ \\
\hline & 20 & 40 & 40 & 0 & $2.07 \pm 0.10$ & $13.42 \pm 0.31$ & $6.62 \pm 0.01$ \\
\hline & 21 & 70 & 40 & 0 & $1.15 \pm 0.05$ & $8.03 \pm 0.39$ & $2.20 \pm 0.04$ \\
\hline & 22 & 40 & 40 & 30 & $2.69 \pm 0.13$ & $39.82 \pm 1.29$ & $25.52 \pm 0.28$ \\
\hline & 23 & 70 & 40 & 30 & $3.77 \pm 0.13$ & $42.25 \pm 2.55$ & $37.90 \pm 0.91$ \\
\hline & 24 & 55 & 30 & 0 & $0.76 \pm 0.03$ & $4.72 \pm 0.30$ & $0.86 \pm 3.0 \times 10^{-3}$ \\
\hline & 25 & 55 & 50 & 0 & $1.18 \pm 0.04$ & $7.91 \pm 1.00$ & $2.22 \pm 0.20$ \\
\hline & 26 & 55 & 30 & 30 & $6.05 \pm 0.30$ & $40.98 \pm 4.49$ & $59.04 \pm 2.21$ \\
\hline & 27 & 55 & 50 & 30 & $5.74 \pm 0.29$ & $54.48 \pm 0.83$ & $74.52 \pm 0.47$ \\
\hline & 28 & 55 & 40 & 15 & $3.91 \pm 0.16$ & $38.14 \pm 1.82$ & $35.55 \pm 0.58$ \\
\hline & 29 & 55 & 40 & 15 & $3.33 \pm 0.07$ & $41.33 \pm 0.33$ & $32.72 \pm 1.43$ \\
\hline & 30 & 55 & 40 & 15 & $3.07 \pm 0.12$ & $37.58 \pm 1.09$ & $27.47 \pm 0.07$ \\
\hline
\end{tabular}

Acronyms: Temperature (T), Pressure (P), and Ethanol (co-solvent). Standard deviation was less than $5 \%$ in all operating conditions (SD $\leq 5 \%, n=3)$.

Supplementary Table S1 shows the statistical data of both drying processes with a $p$-value in terms of the goodness of fit of the model. It can be seen that ethanol, as a co-solvent, was a significant variable in the extraction process for two drying methods of biomass. These data are reinforced with the mathematical equations obtained in the statistical section and are summarized for the significant factors and their interactions (ethanol). Equations (2) and (3) were developed for an approximate mathematical model to maximize the extraction yield from Muriellopsis sp. dehydrated using the SD (Equation (2)) and FD (Equation (3)) methods:

$$
\begin{aligned}
& \text { Yield }(\%, w / w)=0.88+0.49 \cdot \text { Ethanol }+0.0001 \cdot \mathrm{T} \cdot \text { Ethanol }-0.001 \cdot \mathrm{P} \cdot \text { Ethanol } 0.0007 \cdot \text { Ethanol }^{2} \\
& \text { Yield }(\%, w / w)=7.85+0.10 \cdot \text { Ethanol }+0.002 \cdot \mathrm{T} \cdot \text { Ethanol }+0.0001 \cdot \mathrm{P} \cdot \text { Ethanol }^{2} 0.002 \cdot \text { Ethanol }^{2}
\end{aligned}
$$

where Yield is extraction yield in $\%, w / w$, Ethanol is co-solvent in $\% v / v, \mathrm{~T}$ is temperature in ${ }^{\circ} \mathrm{C}$, and $\mathrm{P}$ is pressure in MPa. These regression equations mathematically approach a model to maximize the yield from the two biomass drying methods based on the experimental results obtained in this work. Figure 4 also shows the results of extraction yields obtained by using the Pareto chart and RSM (Response Surface Methodology) using conditions such as $40-70{ }^{\circ} \mathrm{C}$ temperature and $0-30 \% v / v$ ethanol (extractant) with the optimal pressure of $30 \mathrm{MPa}$ (original ranging from 30-50 MPa) using the two 
modes of dry biomass by SFE. Figure 4A,B represent the extraction yield of Muriellopsis sp. SD biomass, for which the optimum value was $6.40 \% w / w$ at $57.14{ }^{\circ} \mathrm{C}$ and $30 \mathrm{MPa}$ pressure with $30 \%$ v ethanol as a co-solvent. These data are similar to the experimental conditions shown in Table 2 (run 11) with a value of $7.84 \%$ ( $55^{\circ} \mathrm{C}, 30 \mathrm{MPa}$, and $30 \%$ ethanol). Figure $4 \mathrm{C}, \mathrm{D}$ shows the significant factors obtained by the Pareto charts and the extraction yield obtained by RSM from the FD biomass. Its optimum value was similar to that of SD biomass with $5.96 \%$ at $59.67{ }^{\circ} \mathrm{C}$ temperature and $30 \mathrm{MPa}$ pressure with $30 \% v / v$ ethanol as a co-solvent. In this case, run 26 (see Table 2) was the experimental condition closest to the optimum value, with $6.05 \% w / w$. In the SFE process, the highest extraction yield and recovery of bioactive compounds can be achieved by optimizing some critical parameters. Indeed, many studies have shown an ability to modulate $\mathrm{CO}_{2}$ polarity by using co-solvents such as ethanol, and thereby increasing the extraction yields $[48,49]$. Our results showed an increase in the extraction yields using maximum extractant volume $(30 \% v / v)$, similar to other studies. However, no significant interaction was found between temperature and pressure for the extraction yield in both the drying methods. Conversely, other reports accentuate the effect of factors including pressure or temperature on the extraction yield. Mehariya et al. [50] evaluated the pressure factor for measuring lutein extraction by the SFE process from the green microalga Scenedesmus almeriensis. They reported an increase in its yield with an increase in pressure from 25 to $55 \mathrm{MPa}$ at $50{ }^{\circ} \mathrm{C}$ and above $65^{\circ} \mathrm{C}\left(\mathrm{CO}_{2}\right.$ flow rate of $\left.7.24 \mathrm{~g} / \mathrm{min}\right)$.

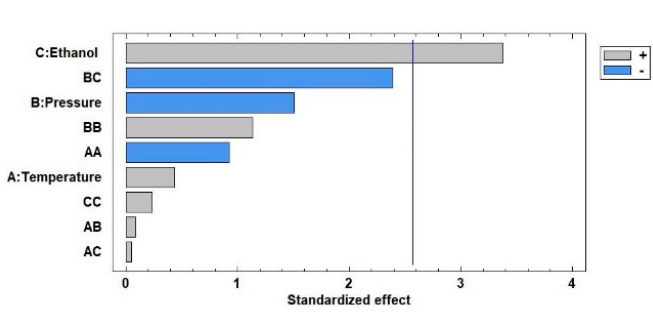

(A)

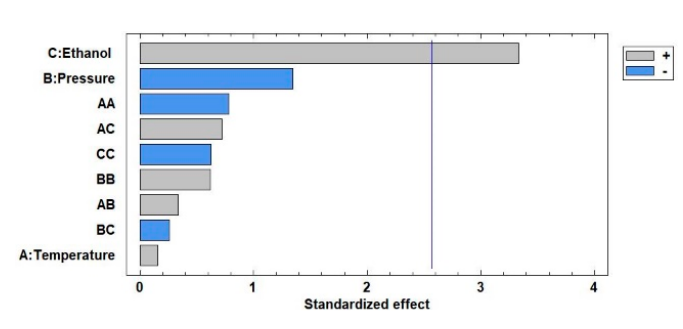

(C)

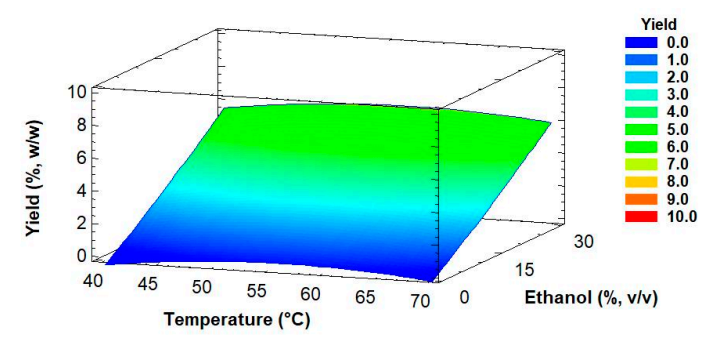

(B)

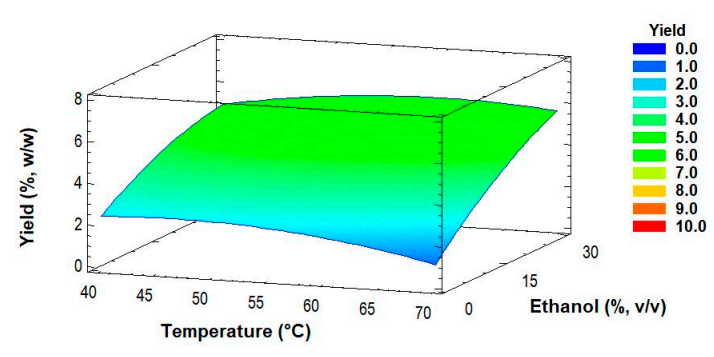

(D)

Figure 4. Pareto Charts and response surface curves of the combined effects of temperature $\left(40-70{ }^{\circ} \mathrm{C}\right)$, pressure (30-50 MPa), and ethanol as co-solvent $(0-30 \% v / v)$ on extraction yield from $(\mathbf{A}, \mathbf{B})$ spray- and (C,D) freeze-dried biomass of Muriellopsis sp. (MCH35), respectively. The \pm signs are interpreted in the Pareto graph according to the area of significance of factor or interaction in the experimental design and Response surface curves were drawn at $30 \mathrm{MPa}$ as optimal pressure.

Generally, an improving trend in the yield was observed in the case of FD biomass. In spite of various alternatives for drying methods available, both SD and FD are the most commonly used drying methods for high-value products [51]. In particular, FD is the best method for water removal and for the conservation of biochemical composition, although it is the most expensive process [51,52]. However, the SD process is faster than other methods, but it can damage different thermolabile components [37]. Therefore, our results showed that the solid-state of water during FD could protect the primary structure of the microalgal biomass with minimal reduction in volume and improving its general extraction yield. 


\subsection{The Effect of Drying Methods on Lutein Recovery of Muriellopsis sp. (MCH35) by SFE}

SFE experiments based on Box-Behnken design were also performed to evaluate lutein content and recovery from Muriellopsis sp. (MCH35) using both drying processes. The SFE study focused on lutein as the main carotenoid as other individual carotenoids were in low levels. The effects of drying methods on lutein recovery are shown in Table 2 and complemented with Supplementary Material (data shown in Table S1). The solvent factor was the most significant in both drying processes. Indeed, the interaction was stronger in the SD process as a quadratic factor. Both drying processes showed almost similar lutein content, with slightly more lutein content in FD biomass. FD biomass showed the highest lutein content $\left(60.69 \mathrm{mg} / \mathrm{g}\right.$ extract) during run 18 at $40{ }^{\circ} \mathrm{C}$ temperature, $50 \mathrm{MPa}$ pressure, and $15 \%$ ethanol, followed by run 27 at $55^{\circ} \mathrm{C}$ temperature, $50 \mathrm{MPa}$ pressure, and $30 \%$ ethanol (54.48 mg/g extract). However, SD biomass showed lutein content of $47.14 \mathrm{mg} / \mathrm{g}$ extract (run 14) under $55^{\circ} \mathrm{C}, 40 \mathrm{MPa}$ pressure, and $15 \%$, followed by run $1\left(45.47 \mathrm{mg} / \mathrm{g}\right.$ extract) at $40{ }^{\circ} \mathrm{C}$ temperature, $30 \mathrm{MPa}$ pressure, and $15 \%$ ethanol. High pressure caused an increase in lutein content in FD biomass, contrary to SD biomass. In both processes, the temperature employed was between 40 and $55{ }^{\circ} \mathrm{C}$ and the amount of ethanol ranged from $15 \%$ to $30 \%, v / v$. It is evident that the main difference in the lutein yield was due to the drying methods. Particularly, high pressure causes a major variation in solvent density so that it can have a good extraction yield for lutein. Moreover, the amount of free water present in Muriellopsis sp. (MCH35) can affect lutein extraction because of the difference in the degree of dehydration between SD and FD methods [52].

In accordance with the above results, lutein recovery obtained by using SD and FD methods is given in Table 2. Figure 5 shows the results obtained by Pareto charts and RSM curves for the combined effects of temperature $\left(40-70{ }^{\circ} \mathrm{C}\right)$, pressure (30-50 MPa), and ethanol as a co-solvent $(0-30 \% v / v)$ on lutein recovery from SD (Figure 5A,B) and FD biomass (Figure 5C,D). The presence of ethanol was significant in both methods. A similar trend was observed in the SD method because, again, the quadratic ethanol factor was relevant in lutein recovery (can be confirmed by Supplementary Material such as Table S1). The mathematical models are included in Equations (4) and (5) for the optimization of lutein recovery from SD and FD microalga, respectively. The equations summarize factors that were significant (ethanol as co-solvent), including their interactions.

$$
\begin{aligned}
& \text { Lutein recovery }(\%, w / w)=32.06+2.48 \cdot \text { Ethanol }+0.0002 \cdot \mathrm{T} \cdot \text { Ethanol }-0.002 \cdot \mathrm{P} \cdot \text { Ethanol }-0.04 \cdot \text { Ethanol }^{2} \\
& \text { Lutein recovery }(\%, w / w)=8.06+0.43 \cdot \text { Ethanol }+0.019 \cdot \mathrm{T} \cdot \text { Ethanol }+0.002 \cdot \mathrm{P} \cdot \text { Ethanol }-0.03 \cdot \text { Ethanol }^{2}
\end{aligned}
$$

where Lutein recovery is measured as $\%, w / w$, Ethanol is co-solvent in $\% v / v, \mathrm{~T}$ is temperature in ${ }^{\circ} \mathrm{C}$, and $\mathrm{P}$ is pressure in MPa. These regression equations again approach a mathematical model obtained by the statistical software to maximize lutein recovery from both drying methods based on the experimental results. The highest lutein recovery obtained in this study was $49.84-74.52 \% w / w$ for the FD biomass in the presence of ethanol $(15-30 \%, v / v)$. Conversely, the pressure and temperature factors were variable and hence were non-significant in the process. Moreover, this set of experimental factors also obtained the highest extraction yield. The optimal factors determined by the statistical analysis for the FD biomass were similar to those cited above. However, optimal lutein recovery was lower than the results mentioned above for the FD biomass, such as $60.47 \% w / w$ at $60{ }^{\circ} \mathrm{C}, 50 \mathrm{MPa}$, and $29.9 \%$ ethanol $(v / v)$, approximately. On the other hand, the SD method achieved poor lutein recovery compared to that obtained by the lyophilization method. Thus, we obtained the best experimental result between $23.25 \%$ and $30.23 \% w / w$ in the presence of ethanol and at intermediate to high temperatures. A low-pressure trend was defined by the SD biomass in the presence of other optimal conditions $\left(58.14^{\circ} \mathrm{C}, 30 \mathrm{MPa}\right.$, and $25.5 \%$ ethanol), with a value of $28.24 \%$ lutein recovery $(w / w)$. 


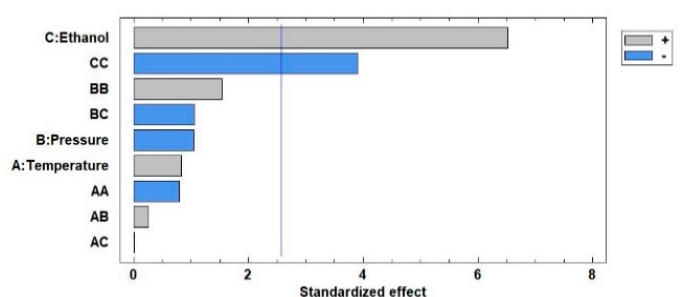

(A)

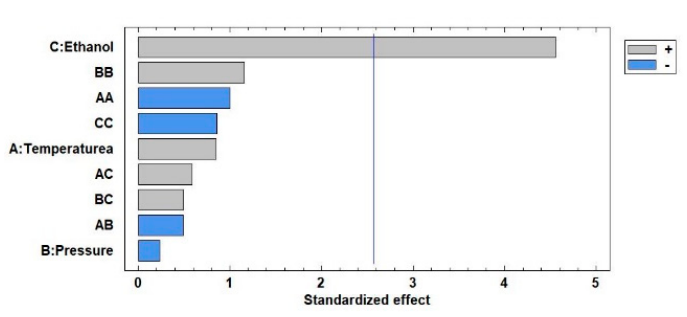

(C)

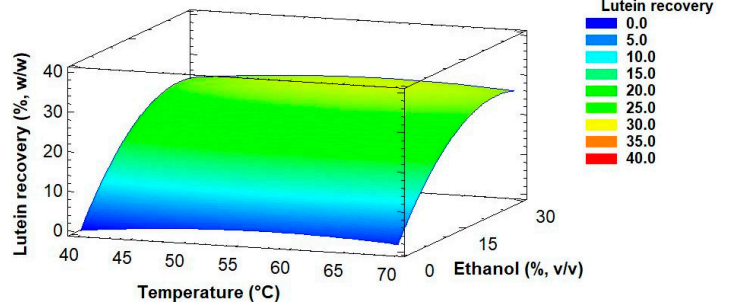

(B)

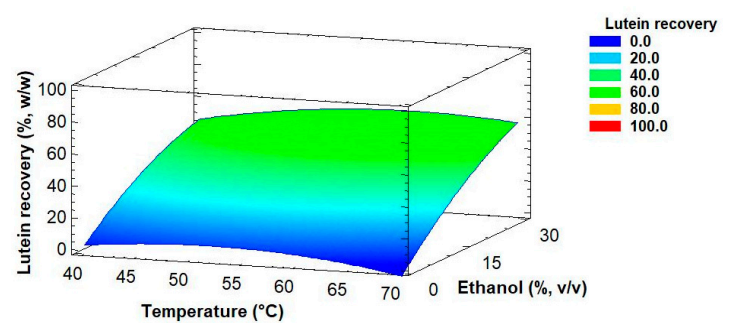

(D)

Figure 5. Pareto Charts and response surface curves of the combined effects of temperature $\left(40-70{ }^{\circ} \mathrm{C}\right)$, pressure (30-50 MPa), and ethanol as a co-solvent $(0-30 \% v / v)$ on lutein recovery from $(\mathbf{A}, \mathbf{B})$ spray- and (C,D) freeze-dried biomass of Muriellopsis sp. (MCH35), respectively. The \pm signs are interpreted in the Pareto graph according to the area of significance of factor or interaction in the experimental design and Response surface curves were made at $30 \mathrm{MPa}$ for spray-dried and $50 \mathrm{MPa}$ for freeze-dried microalga as an optimal pressure.

Other groups of scientists have also studied the effect of supercritical fluid parameters such as pressure, temperature, solvent, and $\mathrm{CO}_{2}$ flow rate on lutein recovery and purity from other sources. Mehariya et al. [50] investigated the effect of pressure (25-55 MPa), temperature (50 and $\left.65{ }^{\circ} \mathrm{C}\right)$, and $\mathrm{CO}_{2}$ flow rate $(7.24$ and $14.48 \mathrm{~g} / \mathrm{min})$ on the green microalga Scenedesmus almeriensis. Their results showed improvements in the lutein recovery $(\sim 98 \%)$ and purity $(\sim 34 \%)$ with an increase in temperature, pressure, and $\mathrm{CO}_{2}$ flow rate. Yen et al. [53] reported 76.7\% lutein recovery from Scenedesmus sp. in the presence of $70{ }^{\circ} \mathrm{C}, 40 \mathrm{MPa}$, and ethanol $(30 \mathrm{~mol} \%)$, which is in the similar range of our results. Wu et al. [54] extracted $87.0 \%$ of lutein from Chlorella pyrenoidosa by SFE in $4 \mathrm{~h}$ in the presence of $50{ }^{\circ} \mathrm{C}, 25 \mathrm{MPa}$, and modified $\mathrm{CO}_{2}$ with $50 \%$ ethanol. The factors optimized for lutein recovery from microalgae by the SFE process in our study are similar to those reported in previous studies. The effect of water content on the Muriellopsis biomass for lutein recovery has been evidenced in our SFE results. Some studies have reported that the optimal parameters for SFE can be obtained from samples that exhibit $3 \%$ to $12 \%$ of water content [55-57]. The presence of moisture in samples can act as a barrier for the diffusion of supercritical $\mathrm{CO}_{2}$ and extracted compounds [57]. However, other studies showed that the presence of water can enhance extraction kinetics and yields from plants and microalgae such as Nannochloropsis oculata [58,59], and water can play the role of co-solvent for polar compounds according to the type of matrix. We got the results emphasizing that optimal supercritical extraction was obtained in the samples with low moisture (lyophilized cells). Although FD is an expensive process for dehydration, an increase of lutein recuperation was significant. This can coalesce with growing the endogenous Muriellopsis sp. in seawater and under arid outdoor conditions to counteract the high costs of the dehydration process. Therefore, Muriellopsis sp. (MCH35) can be used as an efficient lutein producer for biotechnological applications, especially in desert areas. 


\subsection{Global Yield and Kinetic Curve of Muriellopsis sp. (MCH35)}

Based on the yield results obtained for SFE by using Box-Behnken designs from the two modes of dry biomass of Muriellopsis sp., the condition selected for kinetic study was the central point of the experimental design, that is, $55^{\circ} \mathrm{C}, 40 \mathrm{MPa}$, and $\mathrm{CO}_{2}+$ ethanol $(85: 15 \mathrm{v} / \mathrm{v})$ flow rate, since temperature and pressure were non-significant $(p<0.05)$.

Figure $6 \mathrm{~A}, \mathrm{~B}$ show overall extraction curves (OEC) of SD and FD biomass. A recovery of $2.54 \%$ and $5.10 \%$ of extracts was obtained after 150 and $160 \mathrm{~min}$ of extraction for SD and FD biomass, respectively. Similar weights $(\sim 2.0 \mathrm{~g})$ of dry biomass were used for extraction, indicating that a double amount of extract was obtained by FD compared with that of SD. This gives an advantage to the biomass obtained by FD over SD since the resulting final powder is better in quality and quantity. This is due to the fact that drying by sublimation, as in the case of the FD technique, is better.

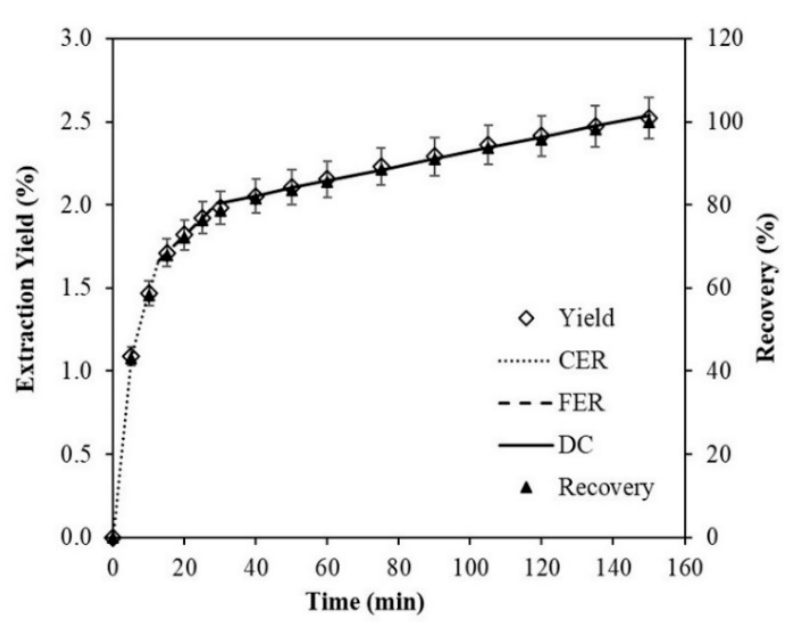

(A)

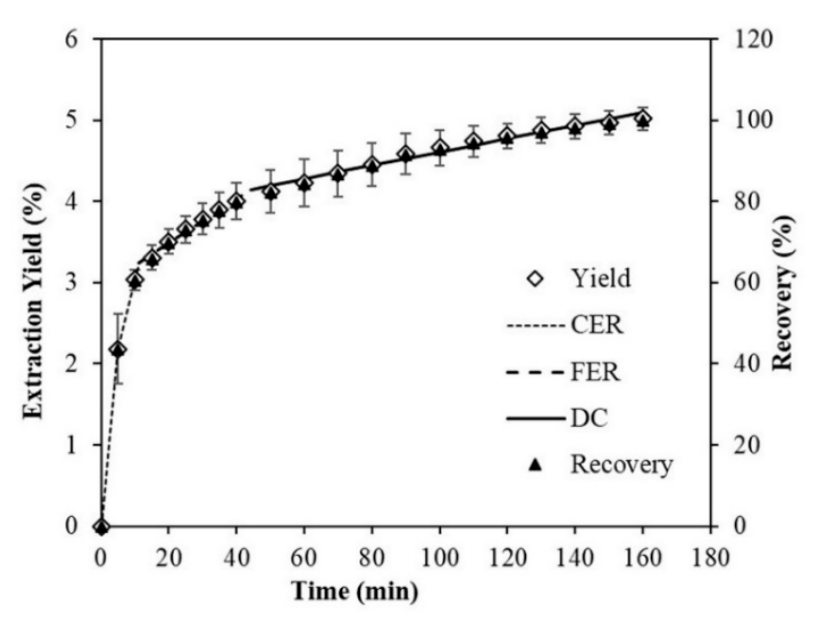

(B)

Figure 6. Overall extraction curves (OECs) of the experimental $(\diamond)$ and predicted data for Spline ( $\cdots$ CER, - FER, - DC) models, and recovery $(\mathbf{\Lambda})$, at $\mathrm{P}=40 \mathrm{MPa}, \mathrm{T}=55^{\circ} \mathrm{C}, \mathrm{CO}_{2}+$ ethanol $(85: 15 \mathrm{v} / \mathrm{v})$ flow rate ( $3.305 \mathrm{~g} / \mathrm{min})$, for Spray-Drying biomass (A), and Freeze-Drying biomass (B). Abbreviations: constant extraction rate period (CER); falling extraction rate period (FER); diffusion-controlled rate period (DC); Pressure (P) and Temperature (T). 
The OEC plotted for SD and FD biomass followed the SFE kinetics that were established by Meireles [60] and Jesus et al. [61]. The extraction process began with the CER period, characterized by the removal of easily extractable compounds by solvent and co-solvent, which was mainly controlled by the convective mass transfer in the fluid film around the powder particles. Following the CER period, the transition period began with a reduced extraction rate, wherein the extraction rate was controlled by mass transfer mechanisms through both convection and diffusion. This period is commonly called the FER period. When easily accessible solute became scarce in the microalgae matrix, intra-particle diffusion became the main mass transfer mechanism during SFE, and hence the OEC assumed a typical shape of diffusion curve with reduced extraction rate.

From the fitted data by the Spline linear model in Figure 6A,B, the OEC parameters were estimated as given in Table 3. The calculated $\mathrm{t}_{\mathrm{CER}}$ were 12.54 and 11.24 min with the accumulated extracts of $1.66 \%$ and $3.25 \%$, and the recovery of $65.85 \%$ and $64.72 \%$ for SD and FD biomass, respectively. This is in agreement with a previous study that reported the recovery between $50 \%$ and $90 \%$ in the CER period [62]. Although $t_{C E R}$ of SD differs by less than $1 \mathrm{~min}$ and about $1.13 \%$ of the recovery compared to FD, the accumulated extract in FD was double that in SD. The calculated $t_{\text {FER }}$ was 29.01 and $44.11 \mathrm{~min}$ for the accumulated extract of $2.01 \%$ and $4.15 \%$, and the total recovery of $79.63 \%$ and $82.70 \%$ for SD and FD biomass, respectively. At this stage, the difference between $t_{F E R}$ of SD and FD was $\sim 15 \mathrm{~min}$, and the accumulated extract of FD was more than double that for SD. In our research, a recovery $>75 \%$ was achieved in the FER period. The $\mathrm{M}_{\mathrm{CER}}$ and $\mathrm{M}_{\mathrm{FER}}$ values represent the extraction rate of the CER and FER periods respectively [61], with values of 0.0026 and $4.6 \times 10^{-4} \mathrm{~g} / \mathrm{min}$ for SD, and 0.0057 and $5.3 \times 10^{-4} \mathrm{~g} / \mathrm{min}$ for FD. Therefore, the extraction rate that produced $\mathrm{CO}_{2}+$ Ethanol flow in the FD biomass was more than double that for SD. These values of the extraction rates were lower than the values reported for $\mathrm{M}_{\mathrm{CER}}$ in peach almond oil (0.0084-0.0752 $\mathrm{g} / \mathrm{min}$ ) [63] and $\mathrm{M}_{\mathrm{CER}}$ and $\mathrm{M}_{\mathrm{FER}}$ of chañar almond oil (0.066-0.0124 g/min) [64].

Table 3. Adjusted parameters of the spline linear model to SFE from Muriellopsis sp. biomass at $55^{\circ} \mathrm{C}$, $40 \mathrm{MPa}$, and $\mathrm{CO}_{2}+$ ethanol $(85: 15 \mathrm{v} / \mathrm{v})$ flow rate.

\begin{tabular}{|c|c|c|c|c|c|c|}
\hline \multirow{3}{*}{ Parameters } & \multicolumn{6}{|c|}{ Stages of the General Extraction Curve } \\
\hline & \multicolumn{3}{|c|}{ Spray-Drying } & \multicolumn{3}{|c|}{ Freeze-Drying } \\
\hline & CER & FER & DC & CER & FER & DC \\
\hline Time (min.) & 12.54 & 29.01 & 150.0 & 11.24 & 44.11 & 160.0 \\
\hline Accumulated extract (\%) & 1.66 & 2.01 & 2.54 & 3.25 & 4.15 & 5.10 \\
\hline Recovery $(\%)$ & 65.85 & 13.78 & 20.37 & 64.72 & 17.98 & 17.30 \\
\hline Total Recovery (\%) & 65.85 & 79.63 & 100.0 & 64.72 & 82.70 & 100.0 \\
\hline $\mathrm{M}(\mathrm{g} / \mathrm{min})$ & 0.0026 & $4.6 \times 10^{-4}$ & $9.1 \times 10^{-5}$ & 0.0057 & $5.3 \times 10^{-4}$ & $1.7 \times 10^{-4}$ \\
\hline Y (mg extract/g biomass) & 15.91 & 3.79 & 5.50 & 30.76 & 9.45 & 9.53 \\
\hline $\begin{array}{c}\text { Y }(\mathrm{g} \text { extract } / \mathrm{g} \\
(\mathrm{CO} 285 \%+\text { ethanol } 15 \%)\end{array}$ & $1.5 \times 10^{-3}$ & $2.4 \times 10^{-4}$ & $5.4 \times 10^{-5}$ & $3.5 \times 10^{-3}$ & $3.2 \times 10^{-4}$ & $1.0 \times 10^{-4}$ \\
\hline $\begin{array}{c}(\mathrm{CO} 285 \%+\text { ethanol } 15 \%) \\
\mathrm{R}^{2}\end{array}$ & 0.9273 & 1.0000 & 1.0000 & 0.9451 & 1.0000 & 1.0000 \\
\hline Drying Methods & \multicolumn{2}{|c|}{$b_{o}$} & $\mathbf{a}_{1}$ & \multicolumn{2}{|c|}{$\mathbf{a}_{2}$} & $\mathbf{a}_{3}$ \\
\hline Spray-Drying & \multicolumn{2}{|c|}{0.7098} & 0.0758 & \multicolumn{2}{|c|}{-0.0547} & -0.0167 \\
\hline Freeze-Drying & \multicolumn{2}{|c|}{1.3251} & 0.1711 & \multicolumn{2}{|c|}{-0.1437} & -0.0192 \\
\hline
\end{tabular}

$b_{0}$ : Linear coefficient of the first line (CER); $a_{1}, a_{2}$ and $a_{3}$ : Slopes of the lines 1,2 , and 3 corresponding to the periods CER, FER, and DC, respectively; $t_{C E R}$, and $t_{F E R}$ : Times in the intercepts of the lines 1 and 2 and the lines 2 and 3 , respectively; $m_{E X T}(t)$ : mass of the extract at time $t$ in each period; $Y_{t}$ : Variable response of the sixth, and the seventh row, for the considered stage (CER, FER, and DC).

On the other hand, Y values (mg extract/g biomass) in the CER and FER periods of FD showed a similar trend as above, since they were 1.9 and 2.5 times higher than the SD values. $Y$ value (g extract/g $\mathrm{CO}_{2}+$ ethanol 85:15 $\left.v / v\right)$ represents the extract ratio in the supercritical phase at the bed outlet and were 2.3 and 1.3 times higher for the CER and FER periods respectively, in the FD biomass than in SD.

In the final stage of the process or DC period, the difference between the FD and SD biomass was observed. Table 3 shows the coefficients of determination $\left(R^{2}\right)$ for all periods, such as CER, FER, and DC obtained by means of the Spline linear model and their corresponding coefficients, such as $b_{0}, a_{1}$, 
$\mathrm{a}_{2}$, and $\mathrm{a}_{3}$. The $\mathrm{CO}_{2}+$ ethanol $(85: 15 \mathrm{v} / \mathrm{v})$ flow rate was $3.305 \mathrm{~g} / \mathrm{min}$ and solvent to feed ratio $(\mathrm{S} / \mathrm{F})$ of 8.2 to 247.1 (5-150 $\mathrm{min}$ ) and 8.2 to 260.5 (5-160 $\mathrm{min}$ ) for SD and FD, respectively. In different studies performed by using the SFE- $\mathrm{CO}_{2}$ technique, Sanzo et al. [65] reported the lutein recovery of $\sim 47 \%$ from the Haematococcus pluvialis dry biomass with the $\mathrm{CO}_{2}$ flow rate of $3.62 \mathrm{~g} / \mathrm{min}, 50{ }^{\circ} \mathrm{C}$ temperature, and $40 \mathrm{MPa}$ pressure in $120 \mathrm{~min}$. Yen et al. [53] reported the lutein recovery of $76.65 \%$ from the Scenedesmus sp. dry biomass with the $\mathrm{CO}_{2}$ flow rate of $1.45 \mathrm{~g} / \mathrm{min}, 30 \%$ ethanol, $47.5^{\circ} \mathrm{C}$ temperature, and $40 \mathrm{MPa}$ pressure in $60 \mathrm{~min}$.

The $\mathrm{CO}_{2}+$ ethanol mixture was efficient for the solubilization of lutein from Muriellopsis sp. (MCH35) under the established conditions studied by us and also supported by findings in other studies on Haematococcus pluvialis [65], Scenedesmus sp. [53], and Scenedesmus almeriensis [50]. Meireles [60] recommended to extend the SFE process up to the end of CER period, where the extraction rate is the highest, and sometimes it is necessary to extend the extraction process more than the CER period to attain the lowest production cost depending on the characteristics of the product to be extracted [66]. In the present study, the process period was up to $60 \mathrm{~min}$ to ensure the complete recovery of the extract of more than $85 \%$.

\section{Material and Methods}

\subsection{Microalgal Strain and Chemicals}

The microalga Muriellopsis sp. (MCH35) was selected for this research and was isolated from freshwater in the arid north of Chile (Antofagasta Region), as previously described by Marticorena et al. [14]. This strain was deposited in the Spanish algae bank with accession number BEA_IDA_0063B. The UMA5 culture medium was of analytical grade and compounds were purchased from Merck (Darmstadt, Germany). The chemicals used for SFE were carbon dioxide (99\% purity), purchased from Indura Group Air Products (Santiago, Chile), and ethanol co-solvent (99.5\%), from Merck (Darmstadt, Germany). Other chemicals such as ultrapure water, ethanol, methanol, hexane, and acetone were of chromatographic grade (Sigma-Aldrich, Santiago, Chile) for the HPLC (Jasco Inc, Tokyo, Japan) system. Individual carotenoid standards such as lutein, zeaxanthin, violaxanthin, astaxanthin, and $\beta$-carotene were also procured from Sigma-Aldrich (Santiago, Chile).

\subsection{Microalgal Culture Conditions}

Muriellopsis sp. (MCH35) was maintained under controlled conditions in $20 \mathrm{~L}$ bottles at $20 \pm 2{ }^{\circ} \mathrm{C}$, under constant illumination at $80 \mu \mathrm{E} / \mathrm{m}^{2} \cdot$ s provided by fluorescent lamps, with constant aeration of $0.1 \mathrm{v} / \mathrm{v} / \mathrm{min}$ without $\mathrm{CO}_{2}$ supply. The culture medium UMA5 was adapted to natural seawater conditions as described by Riveros et al. [28] and Marticorena et al. [14]. The inoculum was sub-cultured during the exponential growth phase on every 12 th day by taking $10 \%$ of the old culture and $90 \%$ of fresh culture medium and were scaled up to open-raceway ponds of the surface of $36 \mathrm{~m}^{2}$ and capacity of $5.4 \mathrm{~m}^{3}$. Subsequently, Muriellopsis sp. (MCH35) cells were adapted to outdoor conditions under natural illumination with incident irradiance being evaluated by the light availability present at the installations of the Universidad Antofagasta (Antofagasta, Chile), where the reactor was located. Subsequently, the culture was maintained as a batch mode for 12 days with controlled $\mathrm{pH}$ by using the automatic injection of $\mathrm{CO}_{2}$. Finally, Muriellopsis sp. (MCH35) was harvested during its exponential growth phase by using a batch centrifuge (GEA separator, AS-1936076 model, Oede, Westphalia, Germany) at a flow rate of $2 \mathrm{~m}^{3} / \mathrm{h}$ and a maximum pressure of $0.3 \mathrm{MPa}$.

\subsection{Growth Measurements}

Dry biomass concentration $\left(\mathrm{C}_{\mathrm{b}}\right)$ was measured using $50 \mathrm{~mL}$ of the culture sample. The samples were passed through fiberglass filters (Ø1.6 $\mu$ Munktell Filter, Falun, Sweden) and were washed with distilled water. They were then dried in an oven at $105 \pm 2{ }^{\circ} \mathrm{C}$ for $2 \mathrm{~h}$ (in triplicate) until the weight was 
stabilized. Biomass concentration was determined gravimetrically. In addition, biomass productivity was calculated in volumetric terms ( $\mathrm{Pb})$. Batch mode Equation (6) is mentioned below:

$$
P b=(C f-C \mathrm{i})(\text { tff-ti) },
$$

where $\mathrm{C}$ is the biomass concentration in $\mathrm{g} / \mathrm{L}$ and $\mathrm{t}$ is the time in days. The subscripts $i$ and $f$ denote initial and final measurements, respectively. On the other hand, an equation for calculating the specific growth rate $(\mu)$ of the culture was mentioned in the text as Equation (1).

In this equation, $\mu$ is the specific growth rate, $C_{i}$ is the initial biomass concentration, and $C$ is the biomass concentration at any time $t$ during the exponential growth phase. The photosynthetic performance $(\mathrm{Fv} / \mathrm{Fm})$ was measured to determine cell viability. The maximum quantum yield of photosynthetic efficiency of photosystem II was achieved in the case of samples that were previously adapted to darkness for $15 \mathrm{~min}$. The AquaPen-C fluorometer (Photon Systems Instruments, Drásov, Czech Republic) was used for this experiment, as described previously by Riveros et al. [28].

\subsection{Drying Treatment on Microalgal Biomass}

The biomass was divided into two groups: SD and FD. In the first group, the SD process was performed by using a LPG-5 Speed centrifuge spray-dryer (Jiangsu, China). The operating conditions for drying were as follows: air temperature of $185 \pm 5^{\circ} \mathrm{C}$, outlet air temperature of $80 \pm 5^{\circ} \mathrm{C}$, and a flow rate of $4 \mathrm{~L} / \mathrm{h}$. In the second group, the FD process was performed by using a Labconco FreeZone $18 \mathrm{~L}$ Benchtop Dry System (Labconco, Kansas City, MO, USA) at a temperature of $-48 \pm 5^{\circ} \mathrm{C}$ and pressure of $2 \mathrm{~Pa}$. Finally, all samples were packed in vacuum sealing plastic bags and stored at $4 \pm 2{ }^{\circ} \mathrm{C}$ in the dark until use.

\subsection{Detecting Individual Carotenoids}

Individual carotenoids were extracted by using $5 \mathrm{mg}$ of two-mode dry biomass for conventional extraction (benchmark extraction) or $50 \mathrm{mg}$ from supercritical fluids (SF) extracts. Saponification of samples was then performed, and a tricomponent solution was added in all the samples as described by Cerón-García et al. [67]. This tricomponent solution was composed of ethanol:hexane:water in a proportion of 77:17:6 $v / v / v$ and contained $0-60 \% w / w$ potassium hydroxide [68]. The supernatant was transferred into an amber vial for chromatographic analysis. Subsequently, individual carotenoids were separated and identified by using the HPLC system (Jasco Inc, Tokyo, Japan). It was equipped with a quaternary pump (PU-2089 s Plus), diode array detector, and RP-18 column (Lichrosphere, $5 \mu \mathrm{m} \times 150 \mathrm{~mm}$ ) by using a method described by Cerón-García et al. [67]. In the mobile phase, solvent A was water/methanol $(2: 8, v / v)$, solvent $B$ was acetone/methanol $(1: 1, v / v)$, and the detection wavelength was $450 \mathrm{~nm}$ at $25^{\circ} \mathrm{C}$ of column temperature. External standards (Sigma-Aldrich) and their corresponding calibration curves were used to identify and quantify individual carotenoids such as lutein, zeaxanthin, violaxanthin, astaxanthin, and $\beta$-carotene. It was performed in triplicate $(n=3)$.

\subsection{Recovery of Individual Carotenoids}

The effect of operating conditions on the extraction of individual carotenoids was expressed in terms of recovery that was calculated on the basis of the initial mass of each compound, as per Equation (7) given below:

$$
\text { Recovery }(\%)=(W c W t) \times 100
$$

where $\mathrm{W}_{\mathrm{C}}$ is the mass of the extracted compound in $\mathrm{mg}$, and $\mathrm{W}_{\mathrm{t}}$ is the theoretical mass of the compound extracted conventionally $(\mathrm{mg})$. Total carotenoids were extracted by the conventional method described in Section 3.5 and defined as benchmark extraction in Table 1. 


\subsection{SFE}

The extraction was also performed by using a Speed Helix supercritical extractor (Applied Separation, Allentown, PA, USA), which was designed by Ruiz-Domínguez et al. [69], and the extraction process is described in detail in Figure 7. For each extraction, $2 \mathrm{~g}$ of SD or FD biomass of Muriellopsis sp. (MCH35) was used. It was previously ground and sieved using a standard sieve of 35 mesh of the Tyler series (particle size $\leq 0.354 \mathrm{~mm}$ ), along with polypropylene wool and glass beads $(\phi=1 \mathrm{~mm})$, which was then inserted into a $24 \mathrm{~mL}$ stainless-steel extraction cell. In all the cases, the $\mathrm{CO}_{2}$ flow rate of $3.62 \mathrm{~g} / \mathrm{min}$ was maintained, and each extraction was performed for $60 \mathrm{~min}$. Extraction conditions for the microalga were selected on the basis of preliminary kinetic studies performed on Muriellopsis sp. (MCH35) and were set for 150-160 min to ensure the complete removal of bioactive compounds. The resulting extracts were collected in vials under dark conditions. The residual ethanol was evaporated under an $\mathrm{N}_{2}$ gas stream avoiding the oxidation of biomolecules in the extracts by using Flexivap Work-Station (Model 109A YH-1, Glas-Col, Terre Haute, IN, USA) for calculating the extraction yield. Then, the dried extracts with $\mathrm{N}_{2}$ atmosphere were stored at $-20 \pm 2{ }^{\circ} \mathrm{C}$ and in the dark until further analysis (at maximum $2 \mathrm{~h}$ ).

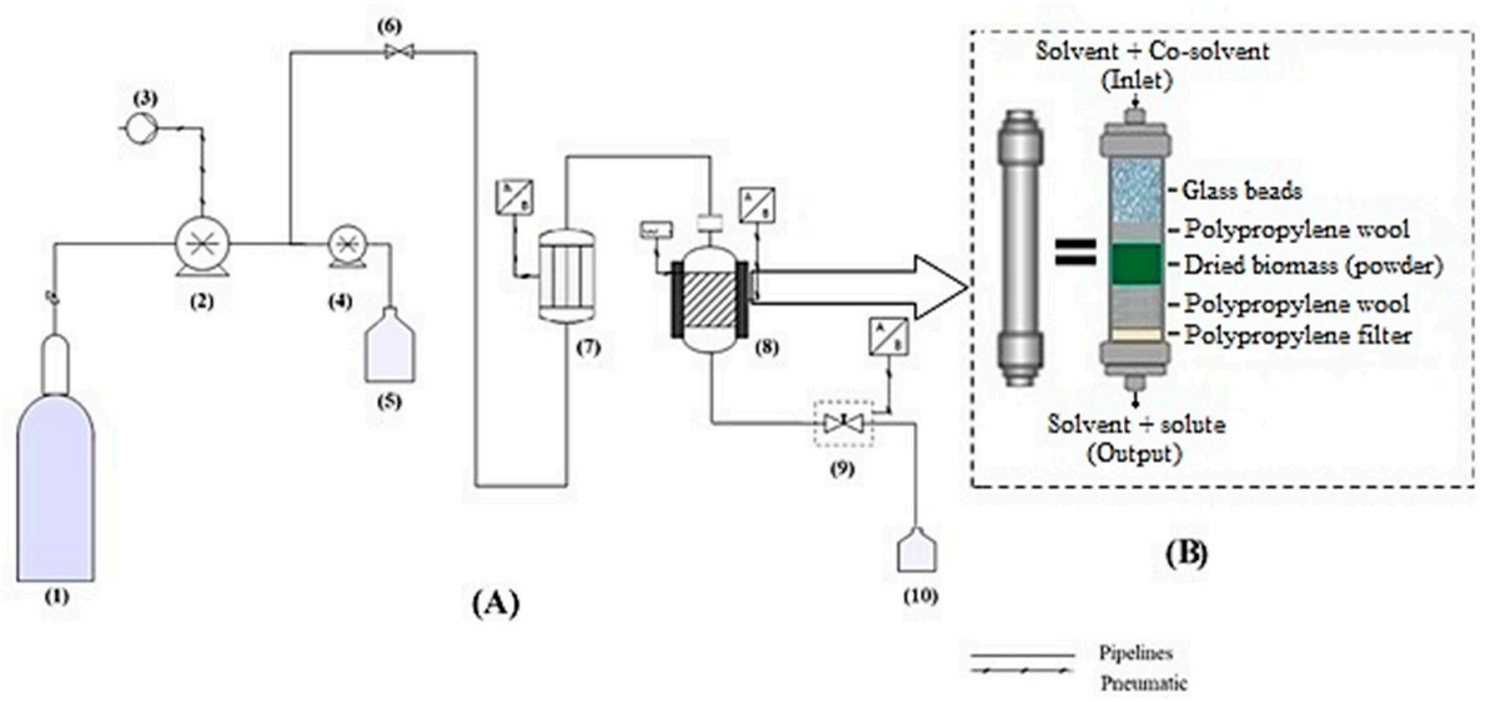

Figure 7. (A) Diagram of the SFE equipment (Applied Separations, Spe-ed, Allentown, PA). (1) $\mathrm{CO}_{2}$ cylinder, (2) $\mathrm{CO}_{2}$ pump, (3) Compressor, (4) Modifier pump, (5) Solvent tank, (6) Inlet valve, (7) Heater, (8) Extraction vessel and oven vessel, (9) Micrometric valve, (10) Sample collection. (B) Schematic diagram of the extraction vessel showing the way in which all elements are arranged.

\subsubsection{Experimental Design}

Two Box-Behnken designs were implemented in random run order, generating 15 experimental conditions for each biomass drying mode independently (30 runs in total, refer to Table 2). Considering both the designs, three factors were evaluated at 3 different experimental levels, such as temperature $\left(40,55\right.$, and $\left.70{ }^{\circ} \mathrm{C}\right)$, pressure $(30,40$, and $50 \mathrm{MPa})$, and percentage of ethanol as a co-solvent $(0 \%, 15 \%$, and $30 \% v / v)$. The effect of the factors on different response variables such as extraction yield $(\mathrm{Y})$ and lutein content and recovery were determined in triplicate $(n=3)$. Other carotenoids were excluded from the study because of their low quantities.

\subsubsection{Mathematical Modeling of Overall Extraction Curve (OEC) and Spline Linear Model}

For kinetic analysis, an OEC between the optimal extraction time versus accumulated extract and lutein recovery was plotted. Extraction kinetics was performed at the central point of the experimental design $\left(40 \mathrm{MPa}, 55^{\circ} \mathrm{C}, 15 \%\right.$ ethanol $v / v$, and flow rate $\left.\mathrm{Q}_{\mathrm{T}}=2 \mathrm{~L} / \mathrm{min}=3.62 \mathrm{~g} \mathrm{CO}_{2} / \mathrm{min}\right)$, as described by Gilbert-López et al. [70]. Each SD and FD biomass sample was collected at preselected intervals of 150 
and $160 \mathrm{~min}$, respectively. In this assay, the extraction yield (Y\%) and lutein recovery (as the majority carotenoid in the profile) were calculated at each point of the curve from both the modes. This assay was performed in duplicate with 15-20 points per sample.

The OEC was fitted to a Spline linear model containing three straight lines Equation (8), as shown in Equations (9)-(11). An adjustment was performed by using PROC REG and PROC NLIN of SAS University Edition Software (https://www.sas.com/en_us/software/university-edition.html) Finally, the fitted data from Equation (7) were plotted by using a Microsoft Excel-2016 spreadsheet. Each fitted line represents the following extraction stages related to the mass transfer mechanism: constant extraction rate (CER) period, falling extraction rate (FER) period that represents the stage at which both convection and diffusion in the solid substratum control the process, and diffusion-controlled (DC) periods, as described by Meireles [60]. In the CER period, the mass transfer rate for the CER period $\left(\mathrm{M}_{\mathrm{CER}}\right)$, as well as the time corresponding to the interception of the two lines ( $\left.\mathrm{t}_{\mathrm{CER}}\right)$, was computed from the Spline linear model. A similar procedure was followed for the FER period, and finally, the DC stage was computed. The experimental data obtained from the OEC were fitted. The mass ratio of the solute in the supercritical phase at the equilibrium cell outlet $\left(\mathrm{Y}_{\mathrm{CER}}\right)$ was obtained by dividing $\mathrm{M}_{\mathrm{CER}}$ by the mean solvent flow rate for the CER period. A similar procedure was employed by Salinas et al. [64] in the mathematical calculations for obtaining almond oil from the chañar fruit (Geoffroea decorticans) by SFE.

$$
y=m_{E x t}=\left(b_{o}-\sum_{i=1}^{i=N} C_{i} a_{i+1}\right)+\sum_{i=1}^{i=N} a_{i} t
$$

For one straight line:

$$
y=m_{E x t}=b_{o}+a_{1} t \text { for } t \leq t_{C E R}
$$

For two straight lines:

$$
y=m_{E x t}=\mathrm{b}_{\mathrm{o}}-\mathrm{t}_{\mathrm{CER}} \mathrm{a}_{2}+\left(\mathrm{a}_{1}+\mathrm{a}_{2}\right) \mathrm{t} \text { for } \mathrm{t}_{\mathrm{CER}}<\mathrm{t} \leq \mathrm{t}_{\mathrm{FER}}
$$

For three straight lines:

$$
y=m_{E x t}=b_{\mathrm{o}}-\mathrm{t}_{\mathrm{CER}} \mathrm{a}_{2}-\mathrm{t}_{\mathrm{FER}} \mathrm{a}_{3}+\left(\mathrm{a}_{1}+\mathrm{a}_{2}+\mathrm{a}_{3}\right) \mathrm{t} \text { for } \mathrm{t}_{\mathrm{FER}}<\mathrm{t}
$$

where $y=$ response variable $=m_{E x t}$ is the mass of extract, $a_{i}(i=0,1,2,3)=$ linear coefficients of lines, $\mathrm{t}=$ time $(\mathrm{min}), \mathrm{t}_{\mathrm{CER}}=\mathrm{CER}$ time $(\mathrm{min})$, and $\mathrm{t}_{\mathrm{FER}}=$ FER time $(\mathrm{min}) . \mathrm{C}_{\mathrm{i}}$ for $\mathrm{i}=1,2$ are the intercepts of these lines (for instance, $C_{1}$ is the intercept of the first and second lines, and $C_{2}$ is the intercept of the second and third lines).

Using the adjusted parameters, $y_{C E R}$ and $y_{F E R}$ calculated from $t_{C E R}$ and $t_{F E R}$ were calculated. Recoveries were then calculated at each time according to Equation (12) given below:

$$
\text { Recovery }(\%)=\frac{y_{t}}{y_{\text {time final OEC }}}(100)
$$

\subsection{Statistical Analysis}

Experimental designs and data analysis were performed by response surface methodology (RSM) and using the Statgraphics Centurion XVI ${ }^{\circledR}$ (StatPoint Technologies, Inc., Warrenton, VA, USA) software. The effects of the factors on response variables in the separation process were assessed by using the pure error and considering a confidence interval of $95 \%$ for all the variables. The effect of each factor on response variables and its statistical significance were analyzed by using analysis of variance (ANOVA) (included in the Supplementary Materials) and the standardized Pareto chart.

The response surfaces of the respective mathematical models were also obtained, and a $p$-value of $\leq 0.05$ was considered significant. All measurements were performed in triplicate $(n=3)$. 
The mathematical relationship of the response with three factors, $X_{1}, X_{2}$, and $X_{3}$, involved in the design was approximated by using quadratic polynomial Equation (13) (second degree):

$$
Z=\beta_{0}+\beta_{1} X_{1}+\beta_{2} X_{2}+\beta_{3} X_{3}+\beta_{12} X_{1} X_{2}+\beta_{13} X_{1} X_{3}+\beta_{23} X_{2} X_{3}+\beta_{11} X_{1}^{2}+\beta_{22} X_{2}^{2}+\beta_{33} X_{3}^{2}
$$

where $Z=$ estimate response, $\beta_{0}=$ constant, $\beta_{1}, \beta_{2}$, and $\beta_{3}=$ linear coefficients, $\beta_{12}, \beta_{13}$, and $\beta_{23}=$ interaction coefficients between the three factors, and $\beta_{11}, \beta_{22}$, and $\beta_{33}=$ quadratic coefficients. The multiple regression analysis was performed to obtain coefficients and equations that can be used to predict the responses.

\section{Conclusions}

The effect of drying methods as a pretreatment for Muriellopsis sp. (MCH35) biomass was studied for the optimization of lutein recovery extracted by the SF process. The production of microalga isolated from the arid north Chile was undertaken in seawater medium (UMA5) and arid outdoor conditions, with the focus on reduction of the operational costs. The production conditions were suitable especially for desert areas where solar radiation is high and fresh water is limited. The strain showed high biomass content and volumetric productivity values between $1.34 \mathrm{~g} / \mathrm{L}$ and $75.73 \mathrm{mg} / \mathrm{L} \cdot \mathrm{d}$ respectively, after 12 days. Moreover, the Muriellopsis cells showed an average photosynthetic efficiency of 0.65 , confirming the microalga was able to adapt to harsh environmental conditions. Moreover, the lutein content was in a similar range with that reported by other lutein-producing microalgae in outdoor conditions. The supercritical experimental outcomes showed that the modifier (ethanol) played a crucial role in the extraction in terms of yield, and lutein content and recovery. However, the parameters such as extraction temperature and pressure were non-significant in the extraction. The maximum optimal yield was similar under both the drying methods at the temperature of the medium to high, low pressure, and maximum extractant ( $30 \% v / v$ ethanol). The maximum lutein recovery of $74 \%(w / w)$ for the FD biomass was 2.5 -fold higher than that for the SD biomass. Therefore, FD was the optimal pre-treatment to enhance the high-valuable extracts of Muriellopsis sp. (MCH35) as microalga adaptable to hostile growth environments for biotechnological applications.

Supplementary Materials: The following are available online at http://www.mdpi.com/1660-3397/18/11/528/s1, Table S1: Regression coefficients (values of variables are specified in their original units) extraction yields (Y), lutein content, and recovery from spray- (SD) and freeze-dried (FD) biomass, statistics for the fit obtained by multiple linear regression.

Author Contributions: Conceptualization, M.C.R.-D. and P.C.; methodology, F.S. and P.M.; software, M.C.R.-D. and P.C.; validation, M.C.R.-D., P.C. and C.R.; formal analysis, M.C.R.-D., P.M. and P.C.; resources, C.S. and C.R.; data curation, P.M., C.S. and F.S.; writing—original draft preparation, M.C.R.-D.; writing-review and editing, P.C.; supervision, P.C. and C.R.; funding acquisition, P.C. and C.R. All authors have read and agreed to the published version of the manuscript.

Funding: This research was funded by projects with public funds of Chile (ANID, National Agency for Research and Development of Chile) such as grants FONDEQUIP EQM-160073 and FONDEF ID18I10095.

Conflicts of Interest: The authors declare no conflict of interest.

\section{References}

1. Forján, E.; Navarro, F.; Cuaresma, M.; Vaquero, I.; Ruíz-Domínguez, M.C.; Gojkovic, Ž.; Vázquez, M.; Márquez, M.; Mogedas, B.; Bermejo, E. Microalgae: Fast-growth sustainable green factories. Crit. Rev. Environ. Sci. Technol. 2015, 45, 1705-1755. [CrossRef]

2. Tomaselli, L. The microalgal cell. In Handbook of Microalgal Culture: Biotechnology and Applied Phycology; Wiley Online Library: Hoboken, NY, USA, 2004; Volume 1, pp. 3-19. [CrossRef]

3. Singh, S.K.; Kaur, R.; Bansal, A.; Kapur, S.; Sundaram, S. Biotechnological exploitation of cyanobacteria and microalgae for bioactive compounds. In Biotechnological Production of Bioactive Compounds; Elsevier: Amsterdam, The Netherlands, 2020; pp. 221-259. 
4. Liu, R.H. Potential synergy of phytochemicals in cancer prevention: Mechanism of action. J. Nutr. 2004, 134, 3479S-3485S. [CrossRef]

5. Michalak, I.; Chojnacka, K. Algae as production systems of bioactive compounds. Eng. Life Sci. 2015, 15, 160-176. [CrossRef]

6. Simopoulos, A.P. Nutrition tid-bites: Essential fatty acids in health and chronic disease. Food Rev. Int. 1997, 13, 623-631. [CrossRef]

7. Kini, S.; Divyashree, M.; Mani, M.K.; Mamatha, B.S. Algae and cyanobacteria as a source of novel bioactive compounds for biomedical applications. In Advances in Cyanobacterial Biology; Elsevier: Amsterdam, The Netherlands, 2020; pp. 173-194.

8. Del Campo, J.A.; García-González, M.; Guerrero, M.G. Outdoor cultivation of microalgae for carotenoid production: Current state and perspectives. Appl. Microbiol. Biotechnol. 2007, 74, 1163-1174. [CrossRef] [PubMed]

9. Gong, M.; Bassi, A. Carotenoids from microalgae: A review of recent developments. Biotechnol. Adv. 2016, 34, 1396-1412. [CrossRef]

10. Guedes, A.C.; Amaro, H.M.; Malcata, F.X. Microalgae as sources of carotenoids. Mar. Drugs 2011, 9, $625-644$. [CrossRef]

11. Dwyer, J.H.; Navab, M.; Dwyer, K.M.; Hassan, K.; Sun, P.; Shircore, A.; Hama-Levy, S.; Hough, G.; Wang, X.; Drake, T. Oxygenated carotenoid lutein and progression of early atherosclerosis: The Los Angeles atherosclerosis study. Circulation 2001, 103, 2922-2927. [CrossRef]

12. Heber, D.; Lu, Q.-Y. Overview of mechanisms of action of lycopene. Exp. Biol. Med. 2002, 227, 920-923. [CrossRef]

13. Landrum, J.T.; Bone, R.A. Lutein, zeaxanthin, and the macular pigment. Arch. Biochem. Biophys. 2001, 385, 28-40. [CrossRef]

14. Marticorena, P.; Gonzalez, L.; Riquelme, C.; Silva Aciares, F. Effects of beneficial bacteria on biomass, photosynthetic parameters and cell composition of the microalga Muriellopsis sp. adapted to grow in seawater. Aquac. Res. 2020. [CrossRef]

15. Rocha, S.; Candia, O.; Valdebenito, F.; Espinoza-Monje, J.F.; Azócar, L. Biomass quality index: Searching for suitable biomass as an energy source in Chile. Fuel 2020, 264, 116820. [CrossRef]

16. Hu, Q. Environmental Effects on Cell Composition; Wiley Online Library: Hoboken, NY, USA, 2004; Volume 1, pp. 83-93.

17. Solovchenko, A.; Khozin-Goldberg, I.; Recht, L.; Boussiba, S. Stress-induced changes in optical properties, pigment and fatty acid content of Nannochloropsis sp.: Implications for non-destructive assay of total fatty acids. Mar. Biotechnol. 2011, 13, 527-535. [CrossRef] [PubMed]

18. Minhas, A.K.; Hodgson, P.; Barrow, C.J.; Adholeya, A. A review on the assessment of stress conditions for simultaneous production of microalgal lipids and carotenoids. Front. Microbiol. 2016, 7, 546. [CrossRef] [PubMed]

19. Fernández-Sevilla, J.M.; Fernández, F.A.; Grima, E.M. Biotechnological production of lutein and its applications. Appl. Microbiol. Biotechnol. 2010, 86, 27-40. [CrossRef]

20. Orikasa, T.; Koide, S.; Okamoto, S.; Imaizumi, T.; Muramatsu, Y.; Takeda, J.-I.; Shiina, T.; Tagawa, A. Impacts of hot air and vacuum drying on the quality attributes of kiwifruit slices. J. Food Eng. 2014, 125, 51-58. [CrossRef]

21. Viswanathan, T.; Mani, S.; Das, K.; Chinnasamy, S.; Bhatnagar, A.; Singh, R.; Singh, M. Effect of cell rupturing methods on the drying characteristics and lipid compositions of microalgae. Bioresour. Technol. 2012, 126, 131-136. [CrossRef]

22. Oliveira, E.G.; Duarte, J.H.; Moraes, K.; Crexi, V.T.; Pinto, L.A. Optimisation of Spirulina platensis convective drying: Evaluation of phycocyanin loss and lipid oxidation. Int. J. Food Sci. Technol. 2010, 45, 1572-1578. [CrossRef]

23. Stramarkou, M.; Papadaki, S.; Kyriakopoulou, K.; Krokida, M. Effect of drying and extraction conditions on the recovery of bioactive compounds from Chlorella vulgaris. J. Appl. Phycol. 2017, 29, 2947-2960. [CrossRef]

24. Chen, C.-L.; Chang, J.-S.; Lee, D.-J. Dewatering and drying methods for microalgae. Dry. Technol. 2015, 33, 443-454. [CrossRef] 
25. Grima, E.M.; Fernández, F.A.; Medina, A.R. 10 Downstream Processing of Cell-mass and Products. In Handbook of Microalgal Culture: Biotechnology and Applied Phycology; Wiley Online Library: Hoboken, NY, USA, 2004; Volume 215.

26. Poojary, M.M.; Barba, F.J.; Aliakbarian, B.; Donsì, F.; Pataro, G.; Dias, D.A.; Juliano, P. Innovative alternative technologies to extract carotenoids from microalgae and seaweeds. Mar. Drugs 2016, 14, 214. [CrossRef] [PubMed]

27. Huang, G.; Chen, F.; Wei, D.; Zhang, X.; Chen, G. Biodiesel production by microalgal biotechnology. Appl. Energy 2010, 87, 38-46. [CrossRef]

28. Riveros, K.; Sepulveda, C.; Bazaes, J.; Marticorena, P.; Riquelme, C.; Acién, G. Overall development of a bioprocess for the outdoor production of Nannochloropsis gaditana for aquaculture. Aquac. Res. 2018, 49, 165-176. [CrossRef]

29. San Pedro, A.; González-López, C.; Acién, F.; Molina-Grima, E. Outdoor pilot production of Nannochloropsis gaditana: Influence of culture parameters and lipid production rates in raceway ponds. Algal Res. 2015, 8, 205-213. [CrossRef]

30. González-Garcinuño, Á.; Tabernero, A.; Sánchez-Álvarez, J.M.; del Valle, E.M.M.; Galán, M.A. Effect of nitrogen source on growth and lipid accumulation in Scenedesmus abundans and Chlorella ellipsoidea. Bioresour. Technol. 2014, 173, 334-341. [CrossRef] [PubMed]

31. Sepúlveda, C.; Acien, F.G.; Gómez, C.; Jiménez-Ruiz, N.; Riquelme, C.; Molina-Grima, E. Utilization of centrate for the production of the marine microalgae Nannochloropsis gaditana. Algal Res. 2015, 9, 107-116. [CrossRef]

32. Chew, K.W.; Chia, S.R.; Show, P.L.; Yap, Y.J.; Ling, T.C.; Chang, J.-S. Effects of water culture medium, cultivation systems and growth modes for microalgae cultivation: A review. J. Taiwan Inst. Chem. Eng. 2018, 91, 332-344. [CrossRef]

33. Camacho-Rodríguez, J.; González-Céspedes, A.; Cerón-García, M.; Fernández-Sevilla, J.; Acién-Fernández, F.; Molina-Grima, E. A quantitative study of eicosapentaenoic acid (EPA) production by Nannochloropsis gaditana for aquaculture as a function of dilution rate, temperature and average irradiance. Appl. Microbiol. Biotechnol. 2014, 98, 2429-2440. [CrossRef]

34. Murata, N.; Takahashi, S.; Nishiyama, Y.; Allakhverdiev, S.I. Photoinhibition of photosystem II under environmental stress. Biochim. Biophys. Acta 2007, 1767, 414-421. [CrossRef]

35. Morales-Amaral, M.d.M.; Gómez-Serrano, C.; Acién, F.G.; Fernández-Sevilla, J.M.; Molina-Grima, E. Production of microalgae using centrate from anaerobic digestion as the nutrient source. Algal Res. 2015, 9, 297-305. [CrossRef]

36. Del Campo, J.A.; Moreno, J.; Rodríguez, H.; Vargas, M.A.; Rivas, J.; Guerrero, M.G. Carotenoid content of chlorophycean microalgae: Factors determining lutein accumulation in Muriellopsis sp.(Chlorophyta). J. Biotechnol. 2000, 76, 51-59. [CrossRef]

37. Ryckebosch, E.; Muylaert, K.; Eeckhout, M.; Ruyssen, T.; Foubert, I. Influence of drying and storage on lipid and carotenoid stability of the microalga Phaeodactylum tricornutum. J. Agric. Food Chem. 2011, 59, 11063-11069. [CrossRef]

38. Jin, E.; Polle, J.E.; Lee, H.K.; Hyun, S.M.; Chang, M. Xanthophylls in microalgae: From biosynthesis to biotechnological mass production and application. J. Microbiol. Biotechnol. 2003, 13, 165-174.

39. Blanco, A.M.; Moreno, J.; Del Campo, J.A.; Rivas, J.; Guerrero, M.G. Outdoor cultivation of lutein-rich cells of Muriellopsis sp. in open ponds. Appl. Microbiol. Biotechnol. 2007, 73, 1259-1266. [CrossRef] [PubMed]

40. Del Campo, J.A.; Rodríguez, H.; Moreno, J.; Vargas, M.Á.; Rivas, J.; Guerrero, M.G. Lutein production by Muriellopsis sp. in an outdoor tubular photobioreactor. J. Biotechnol. 2001, 85, 289-295. [CrossRef]

41. Molino, A.; Mehariya, S.; Iovine, A.; Casella, P.; Marino, T.; Karatza, D.; Chianese, S.; Musmarra, D. Enhancing biomass and lutein production from Scenedesmus almeriensis: Effect of carbon dioxide concentration and culture medium reuse. Front. Plant Sci. 2020, 11, 415. [CrossRef] [PubMed]

42. Begum, H.; Yusoff, F.M.; Banerjee, S.; Khatoon, H.; Shariff, M. Availability and utilization of pigments from microalgae. Crit. Rev. Food Sci. Nutr. 2016, 56, 2209-2222. [CrossRef]

43. Schalch, W.; Cohn, W.; Barker, F.M.; Köpcke, W.; Mellerio, J.; Bird, A.C.; Robson, A.G.; Fitzke, F.F.; van Kuijk, F.J. Xanthophyll accumulation in the human retina during supplementation with lutein or zeaxanthin-the LUXEA (LUtein Xanthophyll Eye Accumulation) study. Arch. Biochem. Biophys. 2007, 458, 128-135. [CrossRef] 
44. Spolaore, P.; Joannis-Cassan, C.; Duran, E.; Isambert, A. Commercial applications of microalgae. J. Biosci. Bioeng. 2006, 101, 87-96. [CrossRef]

45. Kim, H.M.; Jung, J.H.; Kim, J.Y.; Heo, J.; Cho, D.H.; Kim, H.S.; An, S.; An, I.S.; Bae, S. The Protective Effect of Violaxanthin from Nannochloropsis oceanica against Ultraviolet B-Induced Damage in Normal Human Dermal Fibroblasts. Photochem. Photobiol. 2019, 95, 595-604. [CrossRef]

46. Jyonouchi, H.; Sun, S.; Gross, M. Effect of carotenoids on in vitro immunoglobulin production by human peripheral blood mononuclear cells: Astaxanthin, a carotenoid without vitamin a activity, enhances in vitro immunoglobulin production in response to at-dependent stimulant and antigen. Nutr. Cancer 1995, 23, 171-183. [CrossRef] [PubMed]

47. Di Caprio, F.; Altimari, P.; Pagnanelli, F. Sequential extraction of lutein and $\beta$-carotene from wet microalgae biomass. J. Chem. Technol. Biotechnol. 2020, 95, 3024-3033. [CrossRef]

48. Corzzini, S.C.; Barros, H.D.; Grimaldi, R.; Cabral, F.A. Extraction of edible avocado oil using supercritical CO2 and a CO2/ethanol mixture as solvents. J. Food Eng. 2017, 194, 40-45. [CrossRef]

49. Sosa-Hernández, J.E.; Escobedo-Avellaneda, Z.; Iqbal, H.; Welti-Chanes, J. State-of-the-art extraction methodologies for bioactive compounds from algal biome to meet bio-economy challenges and opportunities. Molecules 2018, 23, 2953. [CrossRef] [PubMed]

50. Mehariya, S.; Iovine, A.; Di Sanzo, G.; Larocca, V.; Martino, M.; Leone, G.P.; Casella, P.; Karatza, D.; Marino, T.; Musmarra, D. Supercritical fluid extraction of lutein from Scenedesmus almeriensis. Molecules 2019, $24,1324$. [CrossRef] [PubMed]

51. Ratti, C. Hot air and freeze-drying of high-value foods: A review. J. Food Eng. 2001, 49, 311-319. [CrossRef]

52. Irzyniec, Z.; Klimczak, J.; Michalowski, S. Freeze-drying of the black currant juice. Dry. Technol. 1995, 13, 417-424. [CrossRef]

53. Yen, H.-W.; Chiang, W.-C.; Sun, C.-H. Supercritical fluid extraction of lutein from Scenedesmus cultured in an autotrophical photobioreactor. J. Taiwan Inst. Chem. Eng. 2012, 43, 53-57. [CrossRef]

54. Wu, Z.; Wu, S.; Shi, X. Supercritical fluid extraction and determination of lutein in heterotrophically cultivated Chlorella pyrenoidosa. J. Food Process Eng. 2007, 30, 174-185. [CrossRef]

55. Smyth, T.J.; Zytner, R.; Stiver, W. Influence of water on the supercritical fluid extraction of naphthalene from soil. J. Hazard. Mater. 1999, 67, 183-196. [CrossRef]

56. Nagy, B.; Simándi, B. Effects of particle size distribution, moisture content, and initial oil content on the supercritical fluid extraction of paprika. J. Supercrit. Fluids 2008, 46, 293-298. [CrossRef]

57. Mouahid, A.; Crampon, C.; Toudji, S.-A.A.; Badens, E. Effects of high water content and drying pre-treatment on supercritical CO2 extraction from Dunaliella salina microalgae: Experiments and modelling. J. Supercrit. Fluids 2016, 116, 271-280. [CrossRef]

58. Crampon, C.; Mouahid, A.; Toudji, S.-A.A.; Lépine, O.; Badens, E. Influence of pretreatment on supercritical CO2 extraction from Nannochloropsis oculata. J. Supercrit. Fluids 2013, 79, 337-344. [CrossRef]

59. Ivanovic, J.; Ristic, M.; Skala, D. Supercritical CO2 extraction of Helichrysum italicum: Influence of CO2 density and moisture content of plant material. J. Supercrit. Fluids 2011, 57, 129-136. [CrossRef]

60. Meireles, M.A.A. Extraction of bioactive compounds from Latin American plants. In Supercritical Fluid Extraction of Nutraceuticals and Bioactive Compounds; CRC Press-Taylor \& Francis Group: Boca Raton, FL, USA, 2008; pp. 243-274.

61. Jesus, S.P.; Calheiros, M.N.; Hense, H.; Meireles, M.A.A. A simplified model to describe the kinetic behavior of supercritical fluid extraction from a rice bran oil byproduct. Food Public Health 2013, 3, 215-222. [CrossRef]

62. Pereira, C.G.; Meireles, M.A.A. Supercritical fluid extraction of bioactive compounds: Fundamentals, applications and economic perspectives. Food Bioprocess Technol. 2010, 3, 340-372. [CrossRef]

63. Mezzomo, N.; Martínez, J.; Ferreira, S.R. Supercritical fluid extraction of peach (Prunus persica) almond oil: Kinetics, mathematical modeling and scale-up. J. Supercrit. Fluids 2009, 51, 10-16. [CrossRef]

64. Salinas, F.; Vardanega, R.; Espinosa-Álvarez, C.; Jimenéz, D.; Muñoz, W.B.; Ruiz-Domínguez, M.C.; Meireles, M.A.A.; Cerezal-Mezquita, P. Supercritical fluid extraction of chañar (Geoffroea decorticans) almond oil: Global yield, kinetics and oil characterization. J. Supercrit. Fluids 2020, 104824. [CrossRef]

65. Sanzo, G.D.; Mehariya, S.; Martino, M.; Larocca, V.; Casella, P.; Chianese, S.; Musmarra, D.; Balducchi, R.; Molino, A. Supercritical carbon dioxide extraction of astaxanthin, lutein, and fatty acids from Haematococcus pluvialis microalgae. Mar. Drugs 2018, 16, 334. [CrossRef] 
66. Del Valle, J.M. Extraction of natural compounds using supercritical CO2: Going from the laboratory to the industrial application. J. Supercrit. Fluids 2015, 96, 180-199. [CrossRef]

67. Cerón-García, M.C.; González-López, C.V.; Camacho-Rodríguez, J.; López-Rosales, L.; García-Camacho, F.; Molina-Grima, E. Maximizing carotenoid extraction from microalgae used as food additives and determined by liquid chromatography (HPLC). Food Chem. 2018, 257, 316-324. [CrossRef] [PubMed]

68. Fernández Sevilla, J.M.; Acién Fernández, F.G.; Molina Grima, E.; Cerón García, M.d.C. Extracción de carotenoides mediante el uso de mezclas ternarias. ES200703145A, 13 November 2016.

69. Ruiz-Domínguez, M.C.; Cerezal, P.; Salinas, F.; Medina, E.; Renato-Castro, G. Application of Box-Behnken Design and Desirability Function for Green Prospection of Bioactive Compounds from Isochrysis galbana. Appl. Sci. Basel 2020, 10, 2789. [CrossRef]

70. Gilbert-López, B.; Mendiola, J.A.; Fontecha, J.; van den Broek, L.A.; Sijtsma, L.; Cifuentes, A.; Herrero, M.; Ibáñez, E. Downstream processing of Isochrysis galbana: A step towards microalgal biorefinery. Green Chem. 2015, 17, 4599-4609. [CrossRef]

Publisher's Note: MDPI stays neutral with regard to jurisdictional claims in published maps and institutional affiliations.

(C) 2020 by the authors. Licensee MDPI, Basel, Switzerland. This article is an open access article distributed under the terms and conditions of the Creative Commons Attribution (CC BY) license (http://creativecommons.org/licenses/by/4.0/). 